Atmos. Chem. Phys. Discuss., 2, 385-430, 2002

www.atmos-chem-phys.org/acpd/2/385/

(C) European Geophysical Society 2002

\title{
The impact of a deep convection on sulfate transport and redistribution
}

V. Spiridonov ${ }^{1}$ and M. Ćurić ${ }^{2}$

${ }^{1}$ Institute of Physics, Faculty of Natural Sciences and Mathematics, St. Cyril and Methodius University, Skopje, Macedonia

${ }^{2}$ Department of Meteorology, Faculty of Physics, University of Belgrade, Yugoslavia

Received: 11 February 2002 - Accepted: 26 March 2002 - Published: 12 April 2002

Correspondence to: V. Spiridonov (vspiridonov@meteo.gov.mk)

\section{ACPD}

2, 385-430, 2002

Impact of a deep convection on sulfate transport

V. Spiridonov and

M. Ćurić

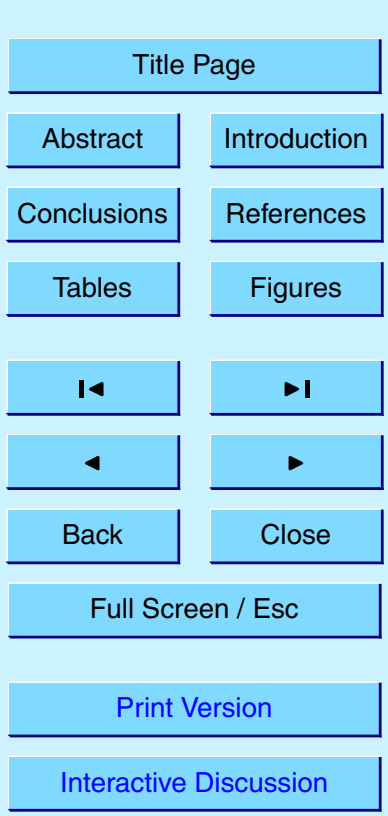

(C) EGS 2002 


\section{Abstract}

A three-dimensional compressible cloud model was used to simulate the processes related to dynamics, microphysics and chemistry of continental non-polluted and continental polluted clouds. The chemical components are formulated in terms of conti5 nuity equations for different chemical species in the aqueous phase within the cloud. Their evolution in this model came from not only by the processes of advection and turbulence transport, but also the chemical reactions and microphysical transfers. The model includes a method of kinetic uptake limitations. Gases with low solubility $\left(\mathrm{H}^{*}<10^{3} \mathrm{~mol} \mathrm{dm}^{-3} \mathrm{~atm}^{-1}\right)$ are in Henry's law equilibrium with temperature dependence of Henry's law coefficients. Seven pollutant groups are currently included in the chemistry parameterization scheme: $\mathrm{S}(\mathrm{IV}), \mathrm{S}(\mathrm{VI}),\left(\mathrm{H}_{2} \mathrm{O}_{2}\right),\left(\mathrm{O}_{3}\right), \mathrm{N}(\mathrm{V}),\left(\mathrm{NH}_{3}\right),\left(\mathrm{CO}_{2}\right)$. The present model contains explicit treatment of $\mathrm{SO}_{2}$ and $\mathrm{O}_{3}$, a kinetic method of gas uptake as well as an improved microphysical parameterization scheme. The primary objective of this model is to study the impact of the deep convection on the pollutant tion, scavenging of aerosol particles and transfer via microphysical transitions among water categories. Two base run simulation parameters are used to initialize the model. The first model run is for the 6 July 1995 event, characterized by intensive convective cloud activity and a large amount of precipitation, manifested as a flashflood. The second one is related to transboundary dust transport and sulfate wet deposition. The chemical field initialization is based on the vertical distribution profiles of gases and aerosols for continental non-polluted and continental polluted background.

The study has revealed the importance of considering interactions between dynamics, microphysics and cloud chemistry. Deep convection in the first analyzed case 25 generates rapid upward and downward transport of pollutants. It stimulates the impact of scavenging processes and microphysical conversions, pollutant redistribution and wet deposition.

We find good agreement between calculated and observed rainfall, $\mathrm{pH}$, sulfate con-
ACPD

$2,385-430,2002$

\section{Impact of a deep convection on sulfate transport}

V. Spiridonov and M. Ćurić

(C) EGS 2002 
centration and wet deposition, in the second simulated case. Aerosol particles partially dissolved in precipitation changed their qualitative and quantitative features, acidity and increment of all chemical components.

A lot of sensitivity tests of the terms included in the chemistry parameterization 5 scheme indicate that assumption of Henry's law equilibrium leads to a factor 2 to 3 underestimate of a soluble gas in cloud water and 3 to 5 in rainwater, respectively. Our calculations demonstrate that assumption of Henry's law leads to a factor of about 1.0 to 1.3 overestimation of the integrated sulfur mass removed by wet deposition. Analysis of the relative contribution of some parameters implies that $20 \%-24 \%$ of 10 total sulfur mass deposited belongs to both nucleation and impact scavenging. Liquid phase oxidation contributed $22 \%$ and $28 \%$ of the total sulfur mass deposited for continental non-polluted and continental polluted background, respectively. Neglecting liquid-ice phase chemical reactions leads to underestimation of the total sulfur mass deposited by about a factor of 1.0 to 1.2 for continental non-polluted and continental

\section{Introduction}

Severe local storms and deep convective clouds are characterized by the enhanced transport of heat and moisture in the upper layers, very strong self-organized flow fields, very complex microphysical transformations and stratospheric penetrations, rapid evolution and dissipation processes. The precipitation is activated in very limited time interval and space and its intensity is manifested by large natural variability. The interactions between clouds and atmospheric pollutants will contribute to the vertical redistribution of the pollutants (Isaac et al., 1982, 1983) and chemical transformation of atmospheric hydrometers. Most of the early models are one-dimensional (e.g. Hales, 1982; Walcek eled results. Studies by Sarma (1986), Tremblay and Leighton (1986) and Niewiadomski (1989) are related to three-dimensional cloud chemistry models formulations and

ACPD

2, 385-430, 2002

\section{Impact of a deep convection on sulfate transport}

V. Spiridonov and M. Ćurić

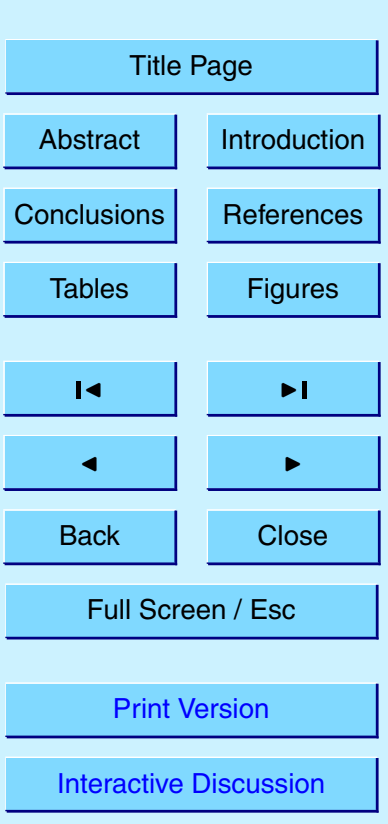

(C) EGS 2002 
their applications in redistribution of chemical species during convection, but they primarily focused on warm convective clouds, ignoring the ice phase microphysical and chemical processes. On the other hand, Wang and Chang (1993a, b) have developed a three-dimensional cloud chemistry model focused on deep convection and chemical 5 processes related to in-cloud transformations and redistribution of pollutants. Flossmann and Wobrock (1996), and Kreidenweis et al. (1997) studied the transport of $\mathrm{SO}_{2}$ in convective clouds and chemical reactions. The Crutzen and Lawrence (2000) study used a three-dimensional global model to examine the impact of convective and large scale precipitation scavenging on the transport of trace gases. More recently, Barth 10 et al. (2001) examined the redistribution of various solubilities during deep convection, while Yin et al. (2001) examined the trace gas redistribution by fully kinetic gas uptake using a two-dimensional dynamic cloud model with detailed microphysics and spectral treatment of gas scavenging. Our objective in the present research is to formulate and test a three-dimensional cloud chemistry model to serve as effective tool to research the effects of deep convection on the redistribution of atmospheric pollutants. To fulfill this requirement, we adopt the basic chemistry concept proposed by Wang and Chang (1993a, b), with modified sulfate chemistry parameterization given by Taylor (1989a, b). In this way we can study the effects of deep convection on the redistribution of atmospheric pollutants and clarify some primary relationships among dynamical, microphysical and chemical processes in a three-dimensional space and complex cloud environment. Our second task is to test the formulation of each chemical productive term and its contribution through a number of sensitivity experiments. Case studies are carried out to examine the performance and capability of the model through comparison between simulated and observed data for a similar case. We first briefly describe the cloud model formulation with short explanations of model dynamics, thermodynamics and microphysics. Section 3 explains model chemistry. Then we explain boundary conditions and numerical technique. Section 5 is related to numerical experiments, initialization, results obtained by this cloud chemistry model, comparison of the results with other studies and comparative analysis. Then the results are followed by discus-

ACPD

$2,385-430,2002$

\section{Impact of a deep convection on sulfate transport}

V. Spiridonov and M. Curić

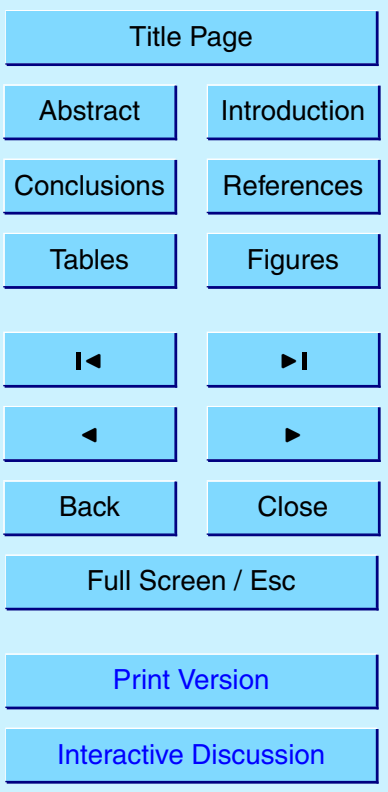

(C) EGS 2002 


\section{Model formulation and description}

2, 385-430, 2002

The model used in this study is a three-dimensional, non-hydrostatic, time dependant, compressible model mainly based on the Klemp and Wilhelmson (1978) dynamics, Lin et. al. (1983) microphysics, and Orville and Kopp (1977) thermodynamics. The present version of the model contains ten prognostic equations: three momentum equations, the pressure and thermodynamic equations, four continuity equations for the water substances, and a subgrid scale kinetic energy equation. All equations are specified in the Cartesian co-ordinate system.

\section{2.1. Dynamics and thermodynamics}

The dynamical part of the model is based on the pressure equation and compressible equations of motions. These equations are derived from the Navier-Stokes equations, using Boussinesq approximation, for the homogeneous and rotating fluid, taking into account advection, turbulent transport, buoyancy (either due to warming or loading

15 hydrometeors), and pressure gradient force. Combining the compressible continuity equation and thermodynamic equation derives the pressure equation. Details could be found in Klemp and Wilhelmson (1978) study.

\subsection{Cloud microphysics}

For the parameterization of the microphysical processes we use the integrated (bulk) 20 water parameterization of Lin et al. (1983) with some significant modifications given by (Ćurić and Janc 1995, 1997 and Ćurić et al., 1998). Six categories of water substances are included: water vapor, cloud water, cloud ice, rain, snow and graupel or hail. Besides the monodisperse size distribution for cloud water and classical MarshalPalmer type size distributions with fixed intercept parameters for rain, hail and snow,

\section{Impact of a deep convection on sulfate transport}

V. Spiridonov and M. Curić

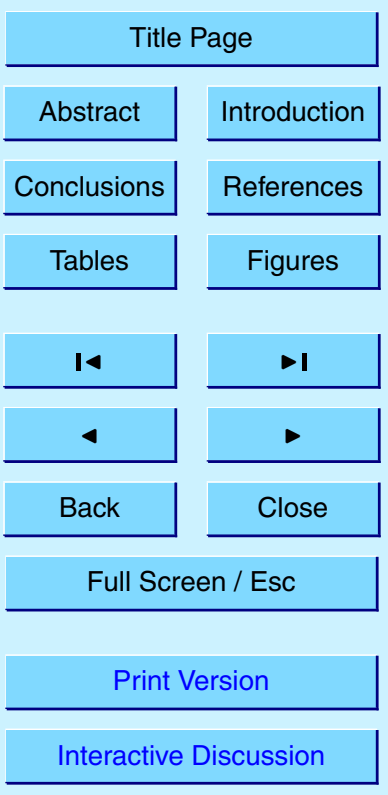

(C) EGS 2002 
the present microphysics allows the Khrgian-Mazin size distribution for the whole liquid water spectrum as one of the commonly used drop size distribution of gamma-type (Ćurić and Janc 1997). Other improvement is in taking realistic hail spectra in accretion equation, by considering only hail sized particles, equal or greater than $0.5 \mathrm{sm}$ in 5 diameter in front of using idealized spectra (Ćurić and Janc, 1995). That significantly improves the quality of parameterization in respect to rain and hail production. The source reference for the scheme to allow coexistence of cloud water and cloud ice in the temperature region of -40 to $0^{\circ} \mathrm{C}$ is Hsie et al. (1980).

\subsection{The model chemistry}

10 The basic motivation for the present study are the research by Taylor (1989a, b), Tremblay and Leighton (1986), Wang and Chang (1993b), Barth et al. (2001), Yin et al. (2001) and Crutzen and Lawrence (2000). In their studies, with except to Crutzen and Lawrence (2000), the authors used as a basic meteorological framework cloud models with different formulations of their dynamical, microphysical and chemical field 15 (Table 1). The chemical model describes the sulfate chemistry inside clouds as it was done in Taylor (1989a, b). We have made some modifications in sulfate parameterization scheme: explicit treating of $\mathrm{SO}_{2}$ and $\mathrm{O}_{3}$ gas phase fields, additional sulfate source terms representing microphysical conversions Lin et al. (1983).

The present 3-D cloud-chemistry model uses as basic mathematical framework a set of conventional continuity equations for each chemical species associated with water category. Cloud chemical fields are expressed through mixing ratios $\left[\mathrm{kg} \mathrm{kg}^{-1}\right.$ (air)], and source terms are given in form $\left[\mathrm{kg} \mathrm{kg}^{-1}\right.$ (air) $] \mathrm{s}^{-1}$. Indexes of chemical fields denote a molecule-hydrometeor field, $\left(q_{\mathrm{SO}_{4, a}}\right)$ is the $\mathrm{SO}_{4}^{-2}$ aerosol mixing ratio, $q_{\mathrm{So}_{4, c}}$ is the $\mathrm{SO}_{4}^{-2}$ cloud water mixing ratio, $q_{\mathrm{SO}_{4, r}}$ is the $\mathrm{SO}_{4}^{-2}$ rainwater mixing ratio (Taylor, $1989 \mathrm{~b}$ ). If we 25
ACPD

$2,385-430,2002$

\section{Impact of a deep convection on sulfate transport}

V. Spiridonov and M. Ćurić

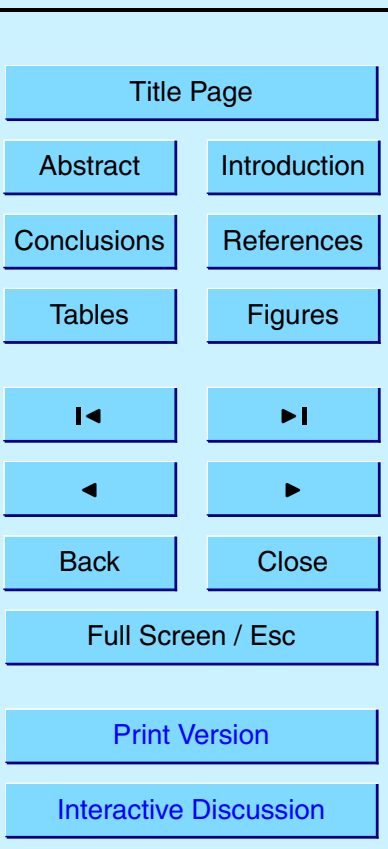

(C) EGS 2002 
following conserving form,

ACPD

$\frac{\partial q_{i, a}}{\partial t}+\frac{\partial q_{i, a} u_{j}}{\partial x_{j}}-q_{i, a} \frac{\partial u_{j}}{\partial x_{j}}=E_{i, a}+S M_{i, a}+S q_{i, a}, \quad j=1,2,3$;

$\frac{\partial q_{i, c}}{\partial t}+\frac{\partial q_{i, c} u_{j}}{\partial x_{j}}-q_{i, c} \frac{\partial u_{j}}{\partial x_{j}}=E_{i, c}+S M_{i, c}+S q_{i, c}$

$\frac{\partial q_{i, r}}{\partial t}+\frac{\partial q_{i, r} u_{j}}{\partial x_{j}}-q_{i, r} \frac{\partial u_{j}}{\partial x_{j}}-S F_{i, r}=E_{i, r}+S M_{i, r}+S q_{i, r}$

${ }_{5} \frac{\partial q_{i, g_{\_} h}}{\partial t}+\frac{\partial q_{i, g_{-} h} u_{j}}{\partial x_{j}}-q_{i, g_{-} h} \frac{\partial u_{j}}{\partial x_{j}}-S F_{i, g_{-} h}=E_{i, g_{-} h}+S M_{i, g_{-} h}+S q_{i, g_{-} h}$

$\frac{\partial q_{i, s}}{\partial t}+\frac{\partial q_{i, s} u_{j}}{\partial x_{j}}-q_{i, s} \frac{\partial u_{j}}{\partial x_{j}}-S F_{i, s}=E_{i, s}+S M_{i, s}+S q_{i, s}$

where $u_{j}$ is wind velocity vector with components $(u, v, w), E_{i, a}, E_{i, c}, E_{i, g_{-} h}$ and $E_{s}$ are the subgrid contribution terms, $S M_{i, a}, S M_{i, c}, S M_{i, g_{-} h}$ and $S M_{s}$ are redistribution terms induced by microphysical conversion processes given by relation,

$S M_{i, w c}=q_{i, w c} q_{m}(w c \geq i) / q_{w c}$

where $q_{m}(w c \geq i)$ is the rate of microphysics transformation derived from the microphysical scheme. During transformation the water category " $w c$ " will lose mass and the category " $i$ " will gain mass. $q_{i, w c}$ is the mixing ratio of pollutant " $i$ " associated with water category " $w c$ " and $q_{w c}$ is the mixing ratio of water category. $S q_{i, a}, S q_{i, c}, S q_{i, r}, S q_{i, g_{-} h}$ 5 and $S q_{i, s}$ denote chemical transformation terms, while the falling terms for the hydrometeors are given by

$S F_{i, r, g_{-} h, s}=\frac{1}{\bar{\rho}} \frac{\partial}{\partial x_{3}}\left(\bar{\rho} V_{r, g_{-} h, s} q_{i, r, g_{-} h, s}\right)$

\section{Impact of a deep convection on sulfate transport}

V. Spiridonov and

M. Ćurić

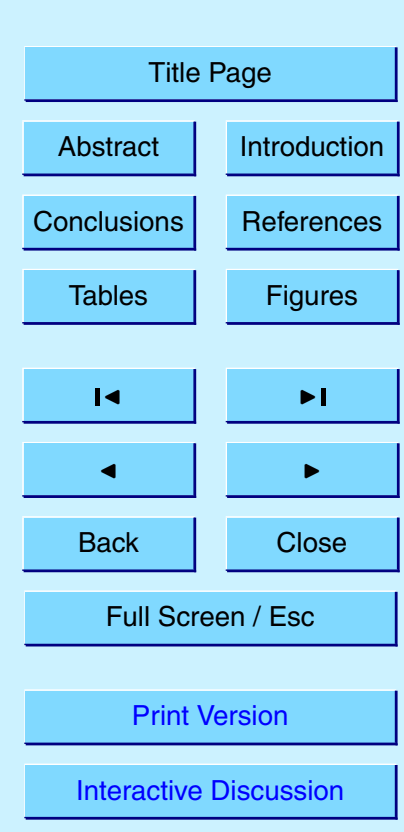

(C) EGS 2002 
where $\bar{\rho}$ is the initial unperturbed value of air density, $V_{r, g_{\perp} h, s}$ are terminal velocities of rain, graupel or hail and snow, respectively. A fully kinetic calculation of gas dissolution into the cloud droplets and raindrops is included in the model. The rate of mass transfer between gas species " $i$ " and spectra of drops with diameter $\alpha$ and number 5 of concentrations $N_{\alpha}$ (per mole air), could be expressed by following relation (Yin et al. (2001)

$$
\frac{d q_{d, i, a}}{d t}=\frac{12 \eta D_{g, i} N_{S h, i}}{R T \alpha^{2}}\left(V_{\alpha} N_{\alpha} P_{i}-\frac{q_{d, i, \alpha}}{H^{*}}\right)
$$

$q_{d, i, \alpha}$ is the molar mixing ratio in respect to air of gas species $i$ inside drops with diameter $\alpha, H_{i}^{*}$ the effective Henry's Law constant of species $i, R$ the universal gas constant, $T$ the temperature; $D_{g, i}$ the diffusivity of gases $i$ in air, $V_{\alpha}$ the volume of drops with diameter $\alpha, P_{i}$ the partial pressure of gas species $i$ in the environment, $N_{S h, i}$ the mass ventilation coefficient (Sherwood number), and $\eta$ a factor which is a function of the Knudsen-number $K_{n}$ and sticking coefficient $\gamma_{i}$ of gas species $i$ on spherical drops. More details could be found in the recently published study by Yin et al. (2001). Gases, 15 (with an effective Henry's law constant $H^{*}<10^{3} \mathrm{~mol} \mathrm{dm}^{-3} \mathrm{~atm}^{-1}$ ) in cloud water and rainwater are assumed to be in equilibrium with the local gas-phase concentrations. These liquid-phase concentrations of each component $(A)$ are calculated according to Henry's law, Hurley (1999)

$$
[A]_{C, r}=\left(L_{C, r} R T K_{H \_}\right)[A]
$$

20 where $L_{c, r}=q_{c, r} \rho / \rho_{W}$ is the liquid cloud water and rainwater volume fraction, $q_{c}$ and $q_{r}$ are mixing ratios of cloud water and rain, $R$ the universal gas constant (0.82) atm $M^{-1} K^{-1}, T$ the temperature in $K, M=$ mol dm ${ }^{-3}$ and $K_{H_{-} A}$ is the effective Henry's Law coefficient for $A$, with temperature dependence of Henry's law coefficients according vant-Hoff's relation

${ }_{25} K_{T}=K_{T 0} \exp \left(-\Delta H / R\left(1 / T-1 / T_{0}\right)\right)$

ACPD

$2,385-430,2002$

\section{Impact of a deep convection on sulfate transport}

V. Spiridonov and M. Ćurić

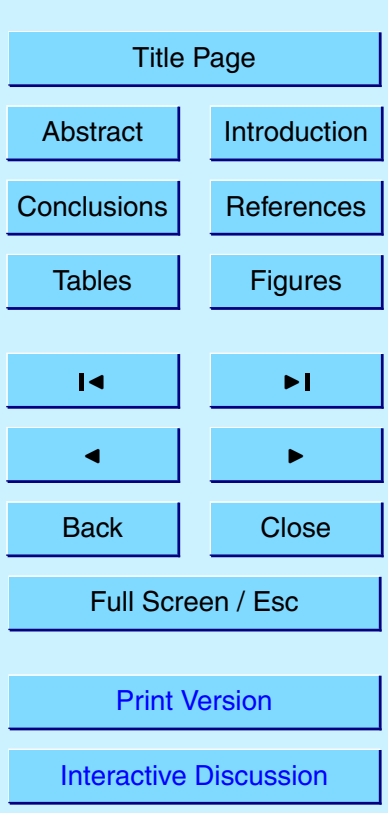

C) EGS 2002 
where $\Delta H$ is the increase of enthalpy induced by chemical reactions, $K_{T 0}$ is the equilibrium constant at a standard $T 0=298 \mathrm{~K}$, and $R$ is the universal gas constant. The schematic of sulfate reactions is shown in Fig. 1 , while the schematic of gas reactions including in sulfate production is illustrates in Fig. 2 . In addition, cloud and raindrops 5 contain dissolved ammonium sulfate $\left(\mathrm{NH}_{4}\right)_{2} \mathrm{SO}_{4}$, which is not created or destroyed in the chemical reactions. The only transitions of $\mathrm{NH}_{4}^{+}$aerosol are scavenging and those following the microphysical transfer (Taylor, 1989b).

Sulfate production and subsequent deposition through precipitation are parameterized by following terms: (SUL1K, SUL15K) representing kinetic gas uptake by cloud o water and rainwater (Fig. 2), (PS, PS9) oxidation of S (IV) to $\mathrm{SO}_{4}^{-2}$ in cloud water and rainwater, (PS3, PS5) nucleation scavenging of $\mathrm{SO}_{4}^{-2}$ aerosol by cloud water and cloud ice, (PS4C, PS4I) scavenging of $\mathrm{SO}_{4}^{-2}$ by Brownian diffusion of cloud water and cloud ice, (PS6, PS7, PS8) are terms representing impact scavenging of $\mathrm{SO}_{4}^{-2}$ aerosol by rain, hail and snow, while PS10 - PS27 are redistribution terms induced by micro15 physics transfer processes. $\mathrm{PH} 17, \mathrm{OHP} 17$ and $\mathrm{PH} 18, \mathrm{OHP} 18$ are reduction terms participating in $\mathrm{S}$ (IV) oxidation processes, while other terms shown on Fig. 2 are source terms of $\mathrm{H}_{2} \mathrm{O}_{2}, \mathrm{SO}_{2}$ and $\mathrm{O}_{3}$ reactions associated with microphysics conversions.

The calculation of the cloud water $\mathrm{pH}$ and rainwater $\mathrm{pH}$ is based on the equilibrium hydrogen ion concentration for $\left[\mathrm{H}^{+}\right]$, which is given by the simple equation (Taylor, 20 1989b):

$\left[H^{+}\right]=0.5\left\{2\left[\mathrm{SO}_{4}^{2-}\right]-\left[\mathrm{NH}_{4}^{+}\right]+\left(\left(2\left[\mathrm{SO}_{4}^{2-}\right]-\left[\mathrm{NH}_{4}^{+}\right]\right)^{2}+4 K_{H}^{*} p_{\mathrm{SO}_{2}}+4 K_{W}\right)^{0.5}\right\}$

The chemical reactions expressed through equilibrium reactions and dissociation and corresponding coefficients are listed in Table 2, while S (IV) oxidation reactions and corresponding coefficients are shown in Table 3.

$25 \mathrm{The}_{4}^{-2}$ and $\mathrm{NH}_{4}^{+}$are distributed as aerosols. Only the aqueous phase chemical reactions are included in the model. The gaseous phase reactions are of importance of long-range transport studies Eliassen et al. (1982), but for the time scale typical of
ACPD

2, 385-430, 2002

\section{Impact of a deep convection on sulfate transport}

V. Spiridonov and M. Ćurić

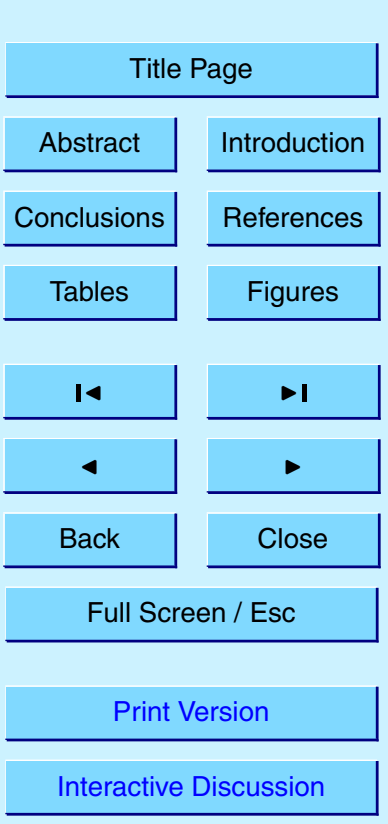

(C) EGS 2002 
Boundary conditions are specified along all sides of the integration domain since the computations take place within a finite model domain. Along the top and bottom of the 5 model domain the normal velocity $\boldsymbol{w}$ is set to zero. That is the same assuming that the normal second derivatives vanish at the boundaries. Lateral boundaries are opened and the time-dependant so the disturbances can pass through by minimal reflection (Duran, 1981).

Model equations are solved on a standard spatially staggered mesh grid. All veloc10 ity component $u_{i}$ are found at one-half grid interval $0.5 \Delta x_{i}$, while scalar variables are defined at the mid point of each grid. Since the model equations are compressible, a time splitting procedure is applied to achieve numerical efficiency. For that purpose, a smaller time step is used to solve sound wave forms, while all other processes are treated with larger time step. The same splitting scheme is applied for each part in our cloud-chemistry model representing advection, subgrid-scale processes, the mass transformation part related to microphysical processes, oxidation, reduction, dissociation or other aqueous phase reaction terms. In order to save computational time we supposed the local chemical equilibrium for chemical species with an effective Henry's law constant $H^{*}<10^{3} \mathrm{~mol} \mathrm{dm}^{-3} \mathrm{~atm}^{-1}$ (Wang and Chang, 1993b).

\section{Numerical experiments}

Many case studies have been performed in order to verify and document the value of the model in contributing to the understanding of convective storm dynamics and microphysics (e.g. Telenta and Aleksić, 1988; Ćurić and Janc, 1993; Ćurić et al., 1999; Spiridonov et al., 1999a, b; Spiridonov and Telenta, 1999b, 2000). The first task in our study is to demonstrate the model ability in simulation of the selected meteorolog-

\section{Impact of a deep convection on sulfate transport}

V. Spiridonov and M. Ćurić

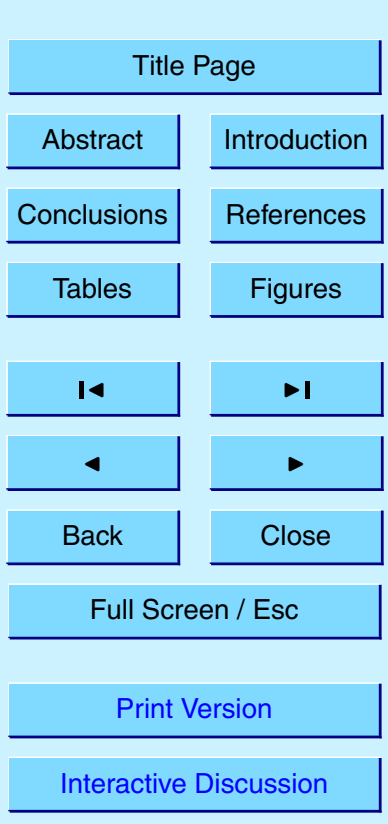

(C) EGS 2002 
ical conditions, related to deep convection and appearance of intensive precipitation, manifested as flashflood (Summer Case). Our objective in that view is to provide more information about the impact of cloud dynamics and microphysics on the vertical redistribution of the pollutants in the atmosphere. Our second task is to examine the 5 sensitivities of cloud chemistry including sulfate production and wet deposition. In that context we shall demonstrate the relative contribution of oxidation processes by comparison of two parallel runs. Then we shall illustrate the time evolution of the cloud water and rainwater $\mathrm{pH}$. The Spring Case is related to transboundary dust transport and its impact on the air and water quality. Finally we shall turn to the comparative 10 and quantitative analysis of the various processes and all productive terms participating in aqueous phase chemical reactions. These questions are examined with cloud chemistry model explained in detail in previous sections. For that purpose we have carried out a series of two- and three-dimensional runs with various assumptions and simplifications.

15 The parallel, three and two-dimensional runs have been carried out in our numerical experiments. The three-dimensional runs are designed to emphasize the importance of strong vertical transport of the chemical species including temperature and moisture and the flows around the cloud. Two-dimensional runs are designed for easily performing model sensitivity tests and for better control of the results of the productive terms of each chemical species.

\subsection{Initial conditions and initialization}

The simulations are initialized using an observed horizontal homogeneous initial field of potential temperature, specific humidity, $u$ and $\boldsymbol{v}$ wind velocity components and pressure taken from an atmospheric sounding for Skopje for Summer Case on 6 July 6 251995 (Fig. 3).

The main characteristics of the sounding are week inversion and the stable layer near the surface, an excess over environmental temperature and moisture deficit at the mid level, and maximum buoyancy forces and updrafts around $500 \mathrm{hPa}$ level. The

ACPD

2, 385-430, 2002

\section{Impact of a deep convection on sulfate transport}

V. Spiridonov and M. Ćurić

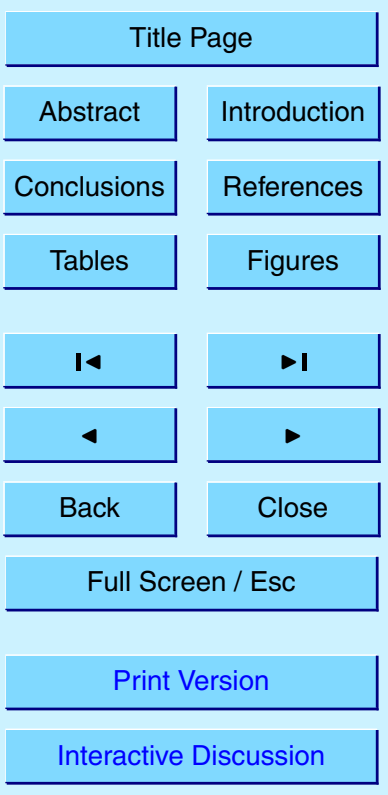

(C) EGS 2002 
wind profile is characterized by weak wind near surface, veering on a subcloud layer, enhanced wind shear on a mid level and strong zonal wind on the upper levels. The cloud chemistry model is initialized using vertical distribution of atmospheric pollutants for continental non-polluted and continental polluted background, respectively. The 5 initial profiles of chemical species for continental non-polluted and continental polluted background are listed in Table 4. The concentrations of $\mathrm{SO}_{2}, \mathrm{H}_{2} \mathrm{O}_{2}, \mathrm{O}_{3}$ and aerosols $\mathrm{NH}_{4}^{+}$and $\mathrm{SO}_{4}^{-2}$ are assumed to fall off exponentially, e.g.

$q_{i}(z)=q_{i}(0) e^{-z / H}$

where $q_{i}(0)$ is the mixing ratio of component $(i)$ at the lowest model level; $H$ is the 10 model scale height.

The model domain for this study is $45 \times 15 \times 14 \mathrm{~km}$ in the three-dimensional $(x, y, z)$ runs. This gives, with a $45 \times 15 \times 28$-grid mesh, a resolution of $1 \mathrm{~km}$ in the horizontal and $0.5 \mathrm{~km}$ vertically. The domain size for two-dimensional runs is $45 \mathrm{~km}$ in the horizontal and $14 \mathrm{~km}$ in the vertical with grid mesh resolution $1 \mathrm{~km}$ in horizontal and $0.5 \mathrm{~km}$ in 15 vertical direction. The temporal resolution of the model is $10 \mathrm{~s}$ time step for integration of the dynamics, microphysics and chemistry and a smaller one is (2s) for solving the sound waves. The same temporal resolution is taken for solving aqueous phase chemistry and transport of chemical species. The integration time for both two and three-dimensional simulations are 180 and $120 \mathrm{~min}$, respectively. Initial impulse for convection is an ellipsoidal warm bubble of the form

$\Delta T=\Delta T_{0} \cos ^{2} \frac{\pi}{2} \beta \quad$ for $\beta<1$

where

$\beta=\left[\left(\frac{x-x_{C}}{x_{*}}\right)^{2}+\left(\frac{y-y_{C}}{y_{*}}\right)^{2}+\left(\frac{z-z_{C}}{z_{*}}\right)^{2}\right]^{1 / 2}$

Here, the subscript $c$ refers to the location of the center of the perturbation, while 25
ACPD

2, 385-430, 2002

\section{Impact of a deep convection on sulfate transport}

V. Spiridonov and M. Ćurić

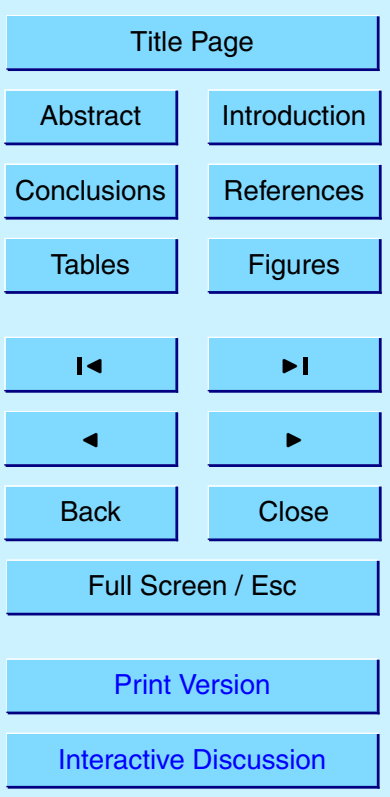

(C) EGS 2002 
$x_{C}=y_{c}=12 \mathrm{~km} ; z_{c}=0.5 \mathrm{~km}, x_{*}=y_{*}=z_{*}=2.8 \mathrm{~km}, z_{*}=0.8 \mathrm{~km}$ and temperature perturbation is maximal in the bubble center and distinguish $\left(T_{0}=4^{\circ} \mathrm{C}\right)$ for Summer and $\left(T_{0}=3.6^{\circ} \mathrm{C}\right)$ for Spring Case, respectively, and exponentially decreased towards zero on the bubble boundary. The initial perturbation of water vapor mixing ratio, caused by 5 this initial temperature perturbation, is calculated with assumption that relative humidity has the same value as the one before the perturbation.

\section{Model results}

\subsection{Simulation of cloud dynamics and microphysics}

The cloud evolution, extensive precipitation occurrence and dissipation stages are well 10 move the cloud towards the supercooled zone, forming traces of ice crystals in $10 \mathrm{~min}$. After $13 \mathrm{~min}$ of the simulation cloud could be described as Cumed with cloud water mixing ratio of $6.8 \mathrm{~g} \mathrm{~kg}^{-1}$ and 2 min later rain occurs. Soon after that massive formation of graupel gives the intensive vertical development of the cloud an important energy source. In 20 min of the simulation time hail reaches maximum mixing ratio $7.7 \mathrm{~g} \mathrm{~kg}^{-1}$. In 25 min cloud top penetrates the tropopause, soon after that our 3-D run indicates rapid transformation of graupel to rain, while the melting graupel also enhanced precipitation, and the mixing ratio of rain increases to its maximum value of $6.5 \mathrm{~g} \mathrm{~kg}^{-1}$. The mature stage of the simulated storm comes after $35 \mathrm{~min}$ of the integration when extensive precipitation occurs. The fallout of hydrometeors weakens the updraft intensity and cuts off supply of moisture from the surface, so the cloud top spreads horizontally forming the characteristic anvil. The weakened surface convergence indicates the entering of dissipate stage, although remaining anvil survives for a much longer time. After 50 min only fragmented structure of the cloud remains in the integration domain. The existing clouds in subsequent simulation time are primarily broken cirrus
ACPD

2, 385-430, 2002

\section{Impact of a deep convection on sulfate transport}

V. Spiridonov and M. Ćurić

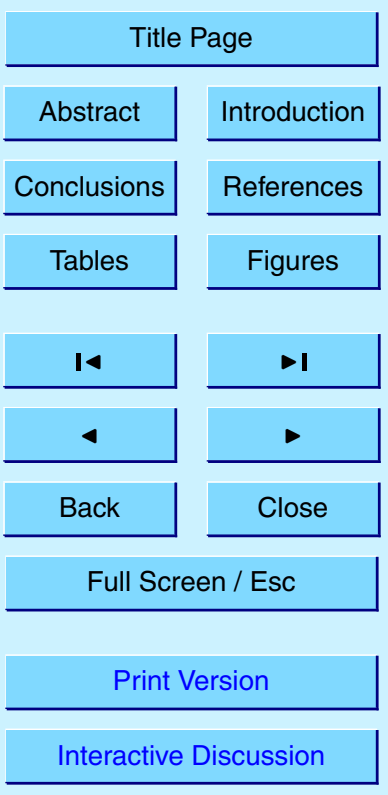

(C) EGS 2002 
clouds. The maximum accumulated rain is $175 \mathrm{~mm}$, and accumulated hail of $1.3 \mathrm{~kg} \mathrm{~m}^{2}$. In summary, a three-dimensional simulation indicates a moderate supercell storm, with the appearance of large amount of precipitation.

The microphysical structure of the storm is examined through calculations of the 5 maximum radar reflectivity factors. The time evolution of the radar reflectivity maps are shown on Fig. 5. Dominant features are temperature perturbation and appearance of the first radar echo $12 \mathrm{~min}$ after initialization. Then we note rapid growth and spreading of the radar reflectivity in the supercooled zone of the cloud model domain. This time of cloud evolution is characterized by intensive microphysics transformation. The formation of precipitation is well evident on the radar reflectivity patterns from 30 to $50 \mathrm{~min}$, when maximum radar reflectivity is found in the warm sector of the model domain. Table 5 shows the comparison between simulated and observed parameters for the same analyzed case.

4.2. A three-dimensional simulation of sulfate transport and redistribution. A deep 15 convective event manifested as flashflooding on 6 July 1995. (Summer Case)

The first analyzed case was a deep convective event, which occurred on 6 July 1995 in southwestern part of Macedonia. This event is a squall line system consisting of several isolated convective storms, which was manifested as flashflooding. Vertical cross sections of total sulfate aerosol concentration (air + cloud + rain) in simulated cloud are presented in Fig. 6, while Fig. 7 shows the three-dimensional view of sulfate transport and redistribution inside convective cloud volume. We note $\mathrm{SO}_{4}^{-2}$ aerosol transport and distribution, which is parallel to cloud formation and evolution. Convergence near cloud base is the result of the mass transfer by nucleation scavenging and Brownian diffusion. The formation of rain leads to a more uniform distribution of aerosol mass. After this, the updrafts are no longer sufficient to maintain the mass flux, and scavenging by rain successively reduces the mass of cloud-dissolved sulfate. The equivalent air concentration of sulfate in precipitation near surface is higher by approximately 2.5
ACPD

2, 385-430, 2002

\section{Impact of a deep convection on sulfate transport}

V. Spiridonov and M. Ćurić

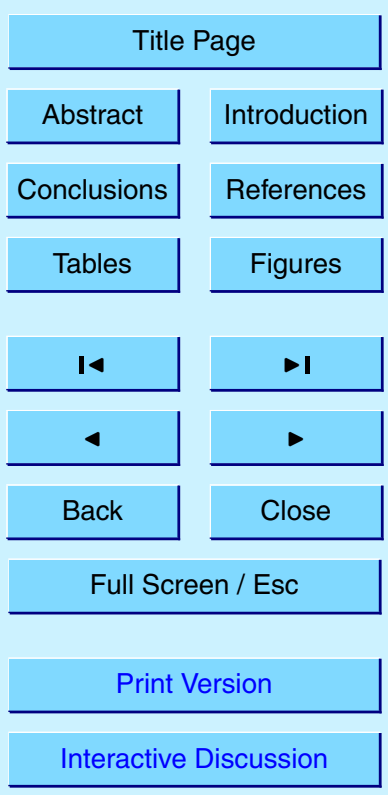


times that of the concentration found in the air at this level. It suggests that both term; oxidation by $\mathrm{O}_{3}$ and $\mathrm{H}_{2} \mathrm{O}_{2}$ in raindrops and impact scavenging by rain contribute in excess of sulfate production near surface. We found that after $40 \mathrm{~min}$ of the simulation time sulfate reaches the ground leading to wet deposition at the surface. Small por5 tions of sulfate mass, which is not scavenged by hydrometeors is advected by flows at upper cloud levels loaded by troposphere wind. As time elapses, evaporation from precipitation becomes so important, that a fraction of the sulfate is transferred back in the air.

Figure 8 shows a time evolution of the sulfate concentration $\left(\mu \mathrm{g} / \mathrm{m}^{3}\right.$ in the $x-z$ plane 10 at $y=8.0$. Sequences on the I.h.s. represent sulfate distribution with turning off all oxidation terms, those on the r.h.s. represent distribution by oxidation on run.

In order to estimate a relative contribution of $\mathrm{SO}_{2}$ oxidation in the production and subsequent deposition of sulfate aerosol for the simulated storm, two cases are examined. The first run is done with turning off all oxidation terms PS2 and PS9 related to oxidation of $\mathrm{SO}_{2}$ by $\mathrm{H}_{2} \mathrm{O}_{2}$ and $\mathrm{O}_{3}$ in cloud droplets and raindrops and $\mathrm{PH} 12, \mathrm{PH} 13$, OHP12 and OHP13 related to reduction of $\mathrm{H}_{2} \mathrm{O}_{2}$ and $\mathrm{O}_{3}$ by $\mathrm{SO}_{2}$, respectively. The second run is performed using the entire chemistry discussed in previous section. As can be seen in Fig. 8 elimination of oxidation terms contribute in appearance of the lower sulfate concentrations in precipitation near ground. This is mainly due to aerosol

scavenging as the remaining pathway for sulfate finding in precipitation. In addition, the oxidation off run also leads to elimination of the reduction terms contributing in oxidation processes in cloud droplets and precipitation.

The time evolution of the $\mathrm{pH}$ factor in cloud droplets and raindrops in 30, 40 and 50 min of the simulation time is shown in Fig. 9. The dashed curves delineate the cloud and rainwater boundary, while solid lines display the $\mathrm{pH}$ factor distribution in cloud and rainwater respectively. The strong gradient of cloud water acidity in early stages of cloud development is due to mass convergence and dissolution of pollutants in cloud water near the central part of cloud. In the cloud mature stage we note successive weakening of the gradient followed by slight lowering of cloud water acidity. In regard

\section{ACPD}

$2,385-430,2002$

\section{Impact of a deep convection on sulfate transport}

V. Spiridonov and M. Ćurić

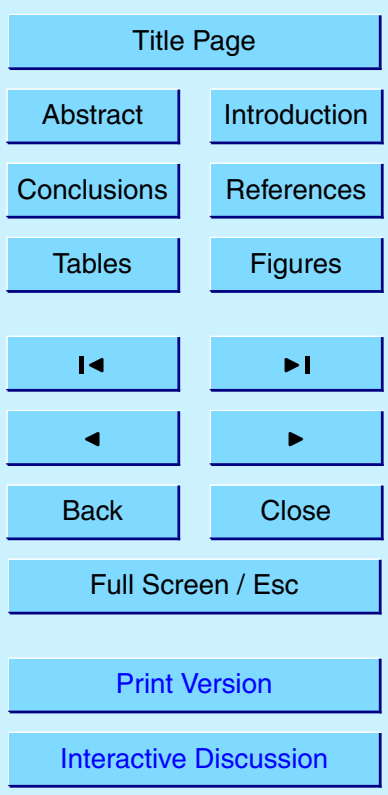

(C) EGS 2002 
to rainwater $\mathrm{pH}$, we note small patterns of rainwater acidity in $20 \mathrm{~min}$ which is due to low rain water concentration during that time. Subsequently, the formation of precipitation induces rain scavenging and dissolution of pollutants, contributing to much more uniform distribution of $\mathrm{pH}$. The averaged $\mathrm{pH}$ of rain near ground is lower than 53.0 and successively increases towards central part of the precipitation zone. Similar results for the $\mathrm{pH}$ distribution but for warm cloud are illustrated in study by Tremblay and Leighton (1986), and for one-dimensional case by Taylor (1989). We note a large acidity gradient in cloud drops of all analyzed cases in cloud development phase. The higher $\mathrm{pH}$ in Taylor (1989b) is obviously due to assumed equilibrium state according to 10 Henry's law and higher concentration value of $\mathrm{SO}_{2}$, and oxidation of $\mathrm{S}$ (IV) to in cloud droplets. An analysis of $\mathrm{pH}$ evolution field in rain on the other side, suggests smaller calculated values in Tremblay and Leighton (1986). This is mainly due to cloud model limitations, warm cumulus convection, ignoring ice-phase processes inside cloud as well as presence of $\left(\mathrm{CO}_{2}\right)$ in electroneutrality relationship increasing cloud acidity.

\subsection{A three-dimensional simulation of sulfate transport and redistribution Transbound-} ary dust transport on 3 April 2000 (Spring Case)

The next experiment is related to transboundary air pollution on 3 April 2000 and its impact on the local-scale air and water quality. Unstable meteorological conditions and deep convection were favorable for dust activity, redistribution and wet deposition.

Rainfall samples have shown visible yellowish aerosol particles, partially dissolved in precipitation changing their qualitative and quantitative features, acidity and content of all components. This statement was supported by chemical analysis of rainfall samples using standard methods of anion elements, such as volume concentration and wet deposition (Nicković et al., 2000; Andreevska et al., 2001). Precipitation samples 25 from meteorological station Lazaropole (located in a rural representative area $1333 \mathrm{~m}$ a.s.I.) were collected every $24 \mathrm{~h}$ with a Wet Only Sampler ARS 1510. Measurements were carried out in the framework of the European Monitoring Environmental Program (EMEP).
ACPD

2, 385-430, 2002

\section{Impact of a deep convection on sulfate transport}

V. Spiridonov and M. Ćurić

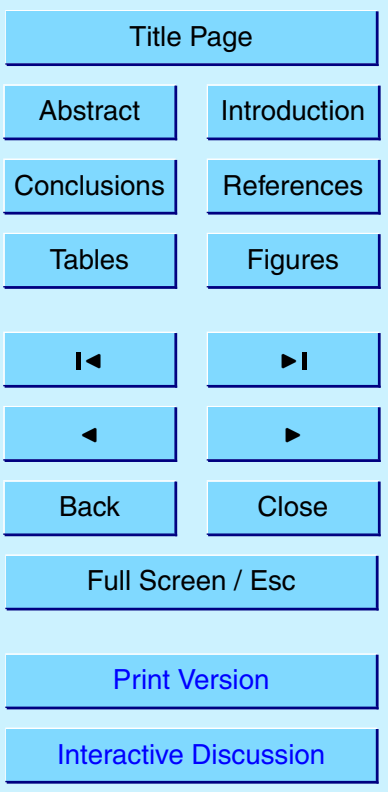

(C) EGS 2002 
The objective of numerical experiment undertaken here is to test the model ability in analyzing the potential influence of long-range transport on cloud-scale air pollution. Other task is to examine if the clouds may act as an important source of sulfate in the air. It is also important to ascertain qualitatively processes by which acidity species are 5 incorporated into precipitation. Finally, the comparison between model results obtained by two-and three-dimensional runs and observational data will be discussed.

The time evolution of sulfate $\left(\mathrm{SO}_{4}^{-2}-\mathrm{S}\right)$ aerosol concentration (air + cloud + rain) in simulated cloud is depicted in Fig. 10. The numerical simulation has shown rapid vertical transport of $\left(\mathrm{SO}_{4}^{-2}\right)$ in cloud formation stage due to the mass transfer by nu10 cleation of the sulfate particle matter. Subsequently this cloud parcel is advected and diffused by the turbulent flow field. Enhanced zonal flows at the upper level rapidly move the polluted cloud into the central part of the integration domain. Early formation of rain contributed in enhanced microphysics sulfate mass conversions among water categories. The much higher sulfate concentration value in $30-40 \mathrm{~min}$ is mainly 15 due to oxidation of $\mathrm{SO}_{2}$ to $\mathrm{SO}_{4}^{-2}$ and scavenging processes. After this the updrafts are not sufficient to maintain sulfate mass at cloud base, and washout by rain gradually reduced cloud dissolved sulfate. It is also seen that rain-laden sulfate reaches the ground after $30 \mathrm{~min}$, leading to wet deposition at the surface. The short time cycles of convective cloud does not allow continuation of the process, and cloud enters dissipate stage. Table 6 lists the parameters that characterized numerical simulation performed here. Among other parameters we calculated maximum volume concentration of $\mathrm{SO}_{4}^{-2}(\mathrm{mg} / \mathrm{l}), \mathrm{pH}$ of cloud and rainwater respectively and total wet deposition $\left(\mathrm{mg} / \mathrm{m}^{2}\right)$, for $120-\mathrm{min}$ simulation.

\subsection{Comparative analysis between simulated and measured results}

One of the verification methods for validity of results obtained by this coupled cloud chemistry model is the comparative analysis. For that purpose we compare the modeled results with those observed and analyzed by standard laboratory methods. Fig-

\section{ACPD}

$2,385-430,2002$

\section{Impact of a deep convection on sulfate transport}

V. Spiridonov and M. Ćurić

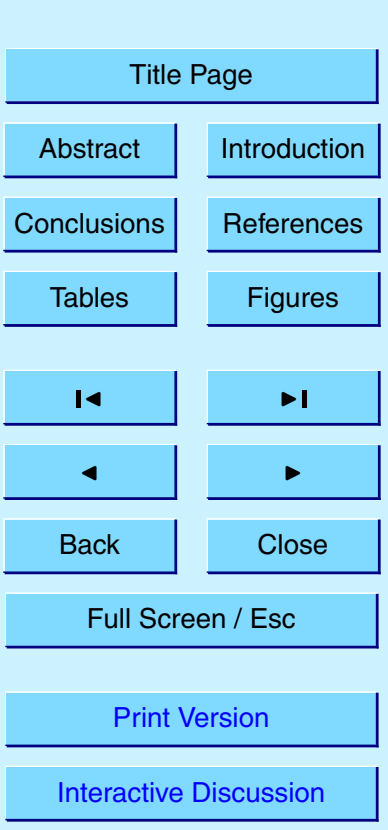

C) EGS 2002 
ures 11 and 12 illustrate observed and measured parameters detected in precipitation samples for period March-April 2000. It is more than obvious that maximum amount of rainfall, $\mathrm{pH}$, conductivity, volume concentration of $\left(\mathrm{SO}_{4}^{-2}-\mathrm{S}\right)$ and wet deposition is well evidenced on 3 April. It is certain that unstable conditions and convection contributed 5 in registration of maximal rainfall in that period, and adequate higher concentration and depositional values.

The comparative analysis has shown good agreement between simulated total accumulated precipitation and those observed. Lower calculated value of $\mathrm{pH}$ in respect to $\mathrm{pH}=8$ registrated in precipitation is due to different applied calculation methods and 10 presence of other components. There is also similarity in calculation total wet deposition of $\left(\mathrm{SO}_{4}^{-2}-\mathrm{S}\right)$ which distinguish $\left(40.16 \mathrm{mg} / \mathrm{m}^{2}\right)$ for $120 \mathrm{~min}$ simulation time. One of the reasons for higher simulated concentration value of $\left(\mathrm{SO}_{4}^{-2}-\mathrm{S}\right) 10.50(\mathrm{mg} / \mathrm{l})$ is the result of using continental background. Beside the lack of initial chemical fields, the comparative analysis has shown a good agreement during the entire analyzed pe15 riod. The laboratory results and peaks have also shown good coincidence with the model-calculated results.

These results are also compared with the results from analyzed precipitation for the main meteorological station (MMS)-Lazaropole taken from the study on air pollution monitoring system in FYROM, published by Japan International Cooperation Agency20 JICA (1999). Results from Table 6 show quite reasonable values of $\mathrm{pH}$ in comparison to annual averaged $\mathrm{pH}$ value (6.22). There is also good agreement between calculated and measured $\mathrm{SO}_{4}^{-2}$ and $\mathrm{NH}_{4}^{+}$ionic concentrations.

4.5. Analysis of the relative contribution of various processes participating in sulfate production
We have also performed two-dimensional simulations and comparative analysis, in order to examine the relative contribution of various processes, which are participated in liquid phase chemical reactions. In this way we could examine the relative contribution
ACPD

2, 385-430, 2002

\section{Impact of a deep convection on sulfate transport}

V. Spiridonov and M. Ćurić

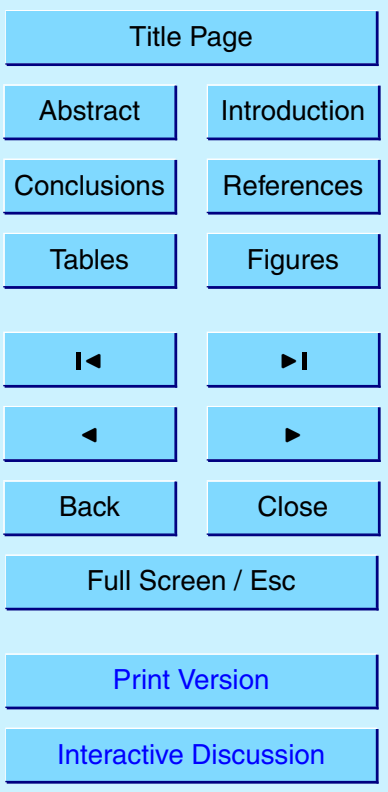

C) EGS 2002 
of various terms contributing in parameterization of cloud chemistry. Many sensitivity tests are performed under different initial conditions and parameters, including or ignoring some components of the liquid phase chemical reactions. Table 7 lists the parameters that distinguish five numerical experiments carried out here, the first one that 5 includes entire chemistry, serves as a basis for comparison with each other.

The parameters listed in Table 7 give a short overview of the relative contribution of separate components, which are included in formation of sulfate budget. The difference between a fully kinetic method of calculation of gas dissolution in cloud and rainwater, respectively as well as using standard Henry's law equilibrium, was found to 10 have significant effect on gas transport.

In Fig. 13 we show sequences of general cloud appearance and redistribution of gases with varying solubility. It could be noticed that Henry's law equilibrium of $\left(\mathrm{O}_{3}\right)$, $\left(\mathrm{SO}_{2}\right)$ and $\left(\mathrm{H}_{2} \mathrm{O}_{2}\right)$ (the panels on the I.h.s. in Fig. 13) leads to higher concentration values compared to method of kinetic gas uptake (panels on the r.h.s. in Fig. 13). This difference is more evident for hydrogen peroxide $\left(\mathrm{H}_{2} \mathrm{O}_{2}\right)$ gas with higher solubility. Assuming Henry's law equilibrium gives about $112 \%$ higher value of sulfate precipitation mass in regard to kinetic method. This percent number is slight higher for continental polluted background and distinguishes $130 \%$. This suggests that models of midlatitude continental storms which neglect kinetic gas uptake limitations will tend to overpredict deposition These values are in relatively good agreement with the results calculated in study by Yin et al. (2001). They found that assuming Henry's law equilibrium leads to a factor 5 underestimation of soluble gas abundance. Barth et al. (2001) have shown that highly soluble tracers $\left(H^{*}=10^{5}\right)$ were reduced by $40-60 \%$ compared to the passive tracer in outflow region. For global model runs in the study by Crutzen and Lawrence (2000), the the soluble gas abundances in the upper troposphere were about $80-90 \%$ and $10-20 \%$ of the insoluble tracers. It appears that less scavenging in the results of soluble tracers for continental cases (29\%) in the study by Yin et al. (2001) is attributed to kinetic uptake limitations in their model.

Analysis of the relative contribution of scavenging processes implied that scavenging

\section{ACPD}

$2,385-430,2002$

\section{Impact of a deep convection on sulfate transport}

V. Spiridonov and M. Ćurić

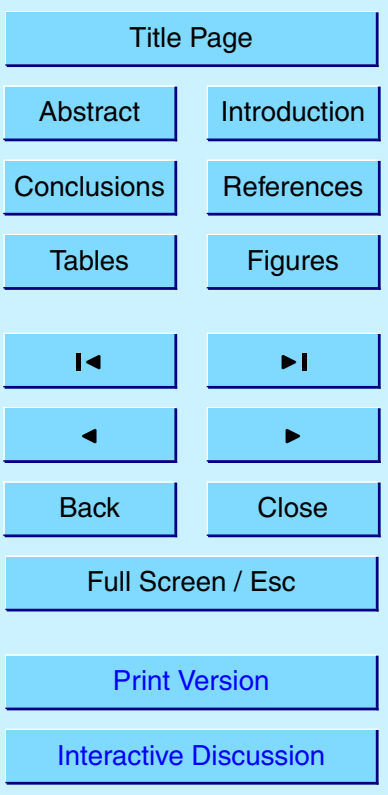

(C) EGS 2002 
for continental non-polluted and continental polluted clouds accounted between $20 \%$ and $24 \%$, respectively. In-cloud scavenging processes in Taylor (1989), accounted between $30 \%$ to $50 \%$, while sub-cloud scavenging contributed for about $25 \%$. These higher calculated percentage numbers in Taylor (1989b), especially for in-cloud scav5 enging are attributed to one-dimensionality of the model used, and assumed Henry's law equilibrium, which leads to strong scavenging of gases.

The role of the ice phase in dynamical and microphysics development of clouds is found to be important. Neglecting liquid-ice phase chemical reactions lead to underestimation of the total sulfur mass removed by wet deposition is increased by about a 10 factor of 1.0 for continental non-polluted and 1.2 for continental polluted distributions relative to the base run.

The oxidation processes have significant effect in sulfate production. Opposite to scavenging, oxidation of $\mathrm{S}$ (IV) to $\mathrm{SO}_{4}^{-2}$ accounted for about $22 \%$ and $28 \%$ for continental non-polluted and continental polluted clouds, respectively. These results are in 15 quite good agreement with those of Wang and Prinn (2000). Their calculations indicated that for about $9.0 \%$ of dissolved $\mathrm{SO}_{2}$ have been converted into aqueous sulfuric acid for $30 \mathrm{~h}$ simulation. A slightly higher estimated value in our study (12.5\%) in that light to those in Wang and Prinn (2000) is probably attributed to different model initializations and using poor ozone (10 ppb), in initial profile of $\mathrm{O}_{3}$ mole fraction. It is also interesting to compare the results here to those in Taylor (1989b). In-cloud oxidation of $\mathrm{SO}_{2}$ contributed from $10 \%$ to $25 \%$ of the total sulfur mass deposited, while sub-cloud oxidation accounted for about 10-35\% for continental non-polluted and continental polluted clouds, respectively. These values seem to be overestimated, as the result of implicit treatment of $\mathrm{SO}_{2}$ and $\mathrm{O}_{3}$ in chemistry scheme and assumed Henry's law equi-

librium. Finally, the integrated sulfur mass removed by wet deposition for continental non-polluted and continental polluted distributions in our study accounted for about 7.52 to $24.08 \mathrm{~kg}$, respectively and are similar to estimated values (7.35 to $24.35 \mathrm{~kg})$ in Taylor (1989). Wang and Prinn (2000) on the other side showed a twice time lower value of liquid-phase sulfate production (141.25 mole) in convective tower and small
ACPD

2, 385-430, 2002

\section{Impact of a deep convection on sulfate transport}

V. Spiridonov and M. Ćurić

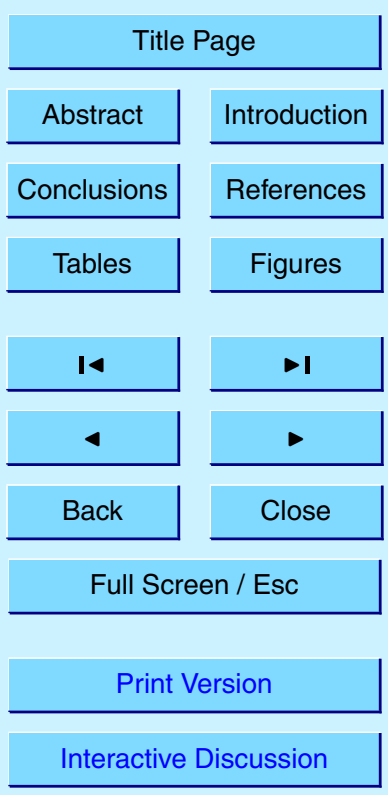

(C) EGS 2002 


\section{Summary and conclusions}

2, 385-430, 2002

A three-dimensional non-hydrostatic cloud chemistry model is used to simulate the sulfate transport and redistribution during deep convection. The chemistry module is 5 formulated in terms of continuity equations for seven chemical species groups (S (IV), $\mathrm{S}(\mathrm{VI}), \mathrm{O}_{3}, \mathrm{H}_{2} \mathrm{O}_{2}, \mathrm{NH}_{3}, \mathrm{~N}(\mathrm{~V}), \mathrm{CO}_{2}$ ), in six different water categories. These equations are representative to describe the impact of advection, diffusion and redistribution of pollutants into atmosphere, induced by microphysics conversions and chemical reactions. Only aqueous-phase sulfate chemistry is presently included in the model as it 10 was done in Taylor (1989b). The modifications are: a fully kinetic calculation of gase uptake by cloud and rainwater, an explicitly treatment of $\mathrm{SO}_{2}$ and $\mathrm{O}_{3}$. and microphysical scheme according Lin et al. (1983) with significant improvements proposed by Curic and Janc, $(1995,1997)$. Model runs were initialized on atmospheric sounding for Skopje, on 6 July 1995 (Summer Case). It was a deep convective event manifested as 15 local flashflooding over southwestern part of Macedonia. The numerical simulations have shown appearance of a storm, characterized by rapid evolution and transformation, formation of intensive precipitation and dissipation. Our results indicate the strong vertical gradient of pollutant mass at cloud base due to mass transfer by aerosol nucleation scavenging or equilibration of gases in cloud droplets. Deep convection induces upward and downward transport of pollutants forming a characteristic parabolic shape pattern. The effects of buoyancy and wind shear intensify the turbulent flow field and diffusion. Horizontal mixing and convergence lead to pollutant accumulation within the cloud although some portions are distributed by the flow, in the cloud upper levels. Ice processes stimulate the impact scavenging and microphysical conversions and transfer of pollutant mass among water categories. Formation of precipitation in cloud developing stage causes rapid redistribution of chemical species. While a large portion of the pollutant mass is being removed by downward precipitation fluxes a small

\section{Impact of a deep convection on sulfate transport}

V. Spiridonov and M. Ćurić

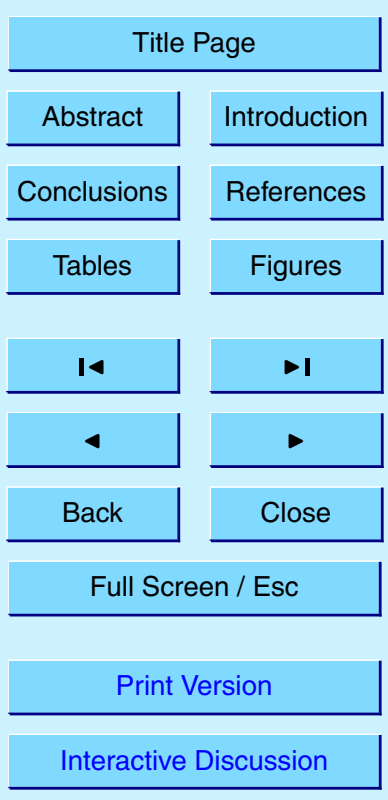

(C) EGS 2002 
part of undissolved aerosol particles or gases are horizontally being distributed by the mean tropospheric wind. The second numerical experiment is done to achieve a better comparison between simulated and observed results. Transboundary dust transport on 3 April obviously had large impact on local scale chemical composition. Unstable 5 atmospheric conditions, convection and rainfall changed the air and water quality. Modeled results are in good agreement with those taken from observations and laboratory measurements. A lot of sensitivity tests of the terms including in chemistry parameterization scheme indicate that assumption of Henry's law equilibrium leads to a factor 2 to 3 underestimate of soluble gas in cloud water and 3 to 5 in rainwater, respectively. 10 Assuming Henry's law equilibrium contributes about one factor higher value of sulfate precipitation mass in regard to kinetic method. This value is slight higher for continental polluted background and distinguishes 1.3. This suggests that models of midlatitude continental storms which neglect kinetic gas uptake limitations will tend to overpredict deposition. Kinetic gas uptake limitations method leads to lower gas scavenging by cloud drops, for a factor of 2 to 3 , while for rainwater distinguishes factor 3 to 5 . Analysis suggested that scavenging for continental non-polluted and continental polluted clouds accounted between $20 \%$ to $24 \%$, respectively.

The role of the ice phase in dynamical and microphysics development of clouds is found to be important. Neglecting liquid phase chemical reactions lead to underestimation of the integrated sulfur mass removed by wet deposition is increased by about a factor of 1.0 for continental non-polluted and 1.2 for continental polluted distributions, relative to the base run.

The oxidation processes have significant effect in the integrated sulfur mass removed by wet deposition. Oxidation of S (IV) to accounted for about $22 \%$ and $28 \%$ for continental non-polluted and continental polluted clouds, respectively. We note that estimated amount of dissolved $\mathrm{SO}_{2}$, which is converted in aqueous sulfuric acid, is about (12.5\%). Finally, the integrated sulfur mass removed by wet deposition in our study accounted for about 7.52 to $24.08 \mathrm{~kg}$ for continental non-polluted and continental polluted background, respectively and these results are similar to those estimated (7.35
ACPD

2, 385-430, 2002

\section{Impact of a deep convection on sulfate transport}

V. Spiridonov and M. Ćurić

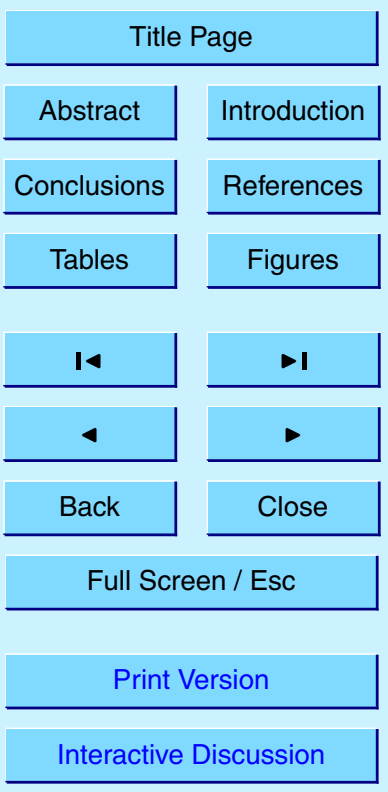


to $24.35 \mathrm{~kg}$ ) in Taylor (1989). Wang and Prinn (2000) on the other side showed a twice time lower value of liquid-phase sulfate production (141.25 mole), in convective tower and small cumulus clouds.

Many questions related to impact of deep convection on redistribution of atmospheric 5 pollutants remain unanswered. Our next task would be to improve the model chemistry including more detail gaseous physics and chemistry, better initialization without random initialization, parameterization of radiation as well as surface chemical processes.

Acknowledgements. First of all we wish to express our gratitude to Mr. Bosko Telenta for his suggestions and advice during development of the chemistry part of his cloud model. We are 10 especially grateful to Dr. Mark Lawrence from the Max Planck Institute for Chemistry for the reviewing of the paper, many helpful comments and clarifying some important points to further improvement of the paper. Two anonymous referees have made many substantial remarks during peer-reviewing process that increased the completeness and clarity of the manuscript.

\section{References}

15 Andreevska, M., Spiridonov, V., and Cvetkovic, J.: Dust transport and deposition in FYROM in April 2000, Journal of Environmental Protection and Ecology 2, 3, 704-716, 2001.

Barth, M. C., Stuart, A. L., and Skamorock, W. C.: Numerical simulation of the July 10 Stratospheric-Tropospheric Experiment: Radiation, Aerosols, and Ozone/Deep Convection storm: Redistribution of soluble tracers, J. Geophys. Res., 106, 12 381-12 400, 2001.

Crutzen, P. J. and Lawrance, M. G.: The impact of precipitation scavenging on the transport of trace gases: A three-dimensional model sensitivity study, J. Atmos. Chem., 37, 81-112, 2000.

Ćurić, M. and Janc, D.: Predictive capabilities of a one-dimensional convective cloud model with forced lifting and a new entrainment formulation, J. Appl. Meteor., 32, 1733-174, 1993.

25 Ćurić, M. and Janc, D.: On the sensitivity of the continuous accretion rate equation used in bulk-water parameterization schemes, Atmos. Res., 39, 313-332, 1995.

Ćurić, M. and Janc, D.: On the sensitivity of hail accretion rates in numerical modeling, Tellus, 49A, 100-107, 1997.

\section{Impact of a deep convection on sulfate transport}

V. Spiridonov and M. Ćurić

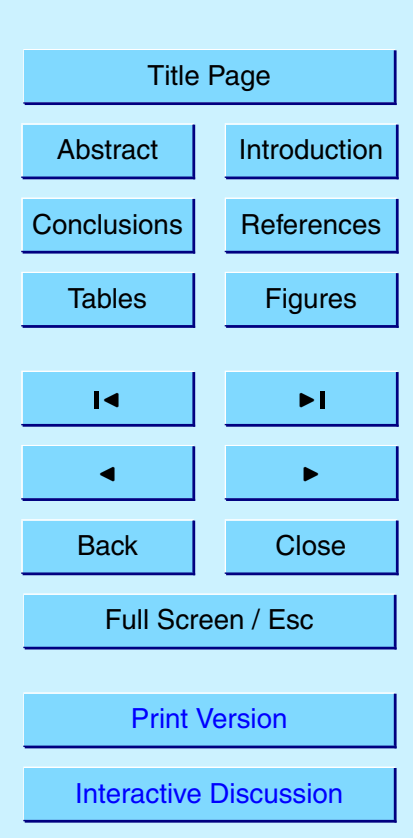


Ćurić, M., Janc, D., and Vuckovic, V.: On the sensitivity of cloud microphysics under influence of cloud drop size distribution, Atmos. Res., 47/48, 1-14, 1998.

Ćurić, M., Janc, D., and Vuckovic, V.: The effects of the hail suppression seeding simulated by the two-dimensional convective cloud model, Seventh WMO Scientific Conference on Weather Modification, Thailand, WMO/TD-No. 936, Vol. II, 515-518, 1999.

Durran, D. R.: The effects of moisture on mountain lee waves. Ph.D. Thesis, Massachusetts Institute of Technology Boston, MA(NTIS PB 82126621), 1981.

Eliassen, A., Hov, O., Isaksen, I. S. A., Saltbones, J., and Stordal, F.: A lagrangian long-range transport model with atmospheric boundary layer chemistry, J. Appl. Meteor., 21, 1645-1661, 1982.

Flossman, A. I. and Wobrock, W.: Venting of gases by convective clouds, J. Geophys. Res., 101, 18639-18649, 1996.

Hales, J. M.: Mechanistic analysis of precipitation scavenging using a one-dimensional time variant model, Atmos. Environ., 16, 177-1783, 1982.

15 Hoffmann, M. R. and Calvert, J. G.: Chemical transformation modules for eulerian acid deposition models, vol. 2. The aqueous phase chemistry. Rep. EPA/600/3-85/017, U.S. Environ. Prot. Agency, Research Triangle Park. N. C., 1985.

Hsie, E. Y., Farley, R. D. and Orville, H. D.: Numerical simulation of ice-phase convective cloud seeding, J. Appl. Meteor., 19, 950-977, 1980.

Hurley, J. P.: The air pollution model (TAMP) Version 1: Techical description and examples, CSIRO Atmospheric Research Techical Paper, No. 43, 1999.

Isaac, G. A., Strapp, J. W., Wiebe, H. A., Leaitch, W. R., Kerr, J. B., Anlauf, K. G., Summers, P. W. and McPherson, J. I.: The role of cloud dynamics in redistributing pollutants and the implications for scavenging studies, Precipitation Scavenging, Dry Deposition and Resuspension.

25 H. R. Pruppacher, R. G. Semonin and W. G. N. Slinn, Coords., Elsevier, 1-13, 1982.

Isaac, G. A., Joe, P. J. and Summers, P. W.: The vertical transport and redistribution of pollutants by clouds, The meteorology of Acid Deposition, (Ed) Samson, P. J., Air Pollution Control Association, 496-512, 1983.

Japan International Cooperation Agency (JICA): The study on air pollution monitoring system in FYROM. Final report (draft), 1999.

Klemp, J. B. and Wilhelmson, R. B.: The simulation of three-dimensional convective storm dynamics, J. Atmos. Sci., 35, 1070-1096, 1978.

Kreidenweis, S. M., Zhang, M., and Taylor, G. R.: The effects of clouds on aerosol and chemical

ACPD

2, 385-430, 2002

\section{Impact of a deep convection on sulfate transport}

V. Spiridonov and M. Ćurić

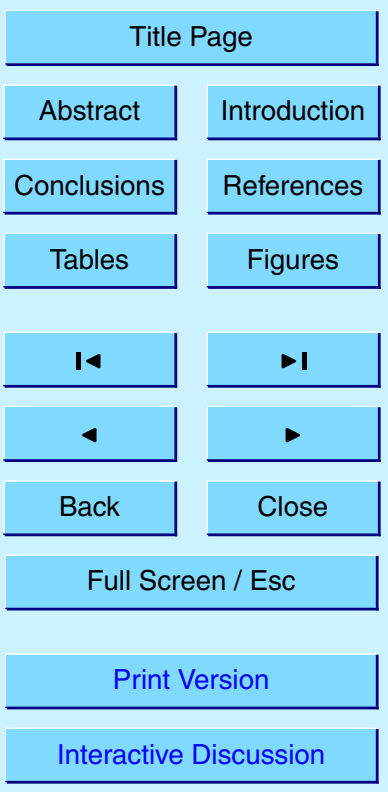

C) EGS 2002 
species production and distribution 2, Chemistry model description and sensitivity analysis, J. Geophys. Res., 102, 23 867-23 882, 1997.

Lin, Y. L., Farley, R. D., and Orville, H. D.: Bulk water parameterization in a cloud model, J. Climate Appl. Meteor., 22, 1065-1092, 1983.

5 Martin, L. R. and Damaschen, D. E.: Aqueous oxidation of sulur dioxide by hydrogen peroxide at low pH, Atmos. Environ., 15, 191-195, 1981.

Nicković, S., Spiridonov, V., Andreevska M., and Music, S.: Simulation and Measurements of Dust Deposition in Macedonia, 15th International Conference on Nucleation \& Atmospheric Aerosols (AIP), Rolla, Missouri, Arizona USA, 2000.

10 Niewiadomski, M.: Sulphur dioxide and sulphate in a three-dimensional field of convective clouds: Numerical simulations, Atmos. Environ., 23, 2, 477-487, 1989.

Orville, H. D. and Kopp, F. J.: Numerical simulation of the history of a hailstorm, J. Atmos. Sci., 34, 1596-1618, 1977.

Pandis, S. N. and Seinfeld, J. H.: Sensitivity analysis of a chemical mechanism for aqueous15 phase atmospheric chemistry, J. Geophys. Res., 94, D1, 1105-1126, 1989.

Sarma, R. A.: Numerical simulation of the formation and transport of sulfate in convective clouds, Ph.D. dissertation, South Dakota School of Mines and Technology, Rep. No. SDSMT/IAS/R-86/04, pp. 188, 1986.

Schwartz, S. E. and White, W. H.: Solubility equilibria of the nitrogen oxides and oxyacids in dilute aqueous solution, in: Advances in Environmental Science and Engineering, (Eds) Pfafflin, J. R. and Ziegler, E. N., 4, 1-45, Gordon and Breach Science Publishers, NY, 1981.

Spiridonov, V., Stefanov, S. and Telenta, B.: Dynamic seeding effects on convective clouds, Seventh WMO Scientific Conference on Weather Modification, Thailand, WMO/TD-No. 936, I, 262-266, 1999a.

Spiridonov, V. and Telenta, B.: The structure of mesoscale convective clouds, Seventh WMO Scientific Conference on Weather Modification, Thailand, WMO/TD-No. 936, I, 270-274, 1999b.

Spiridonov, V. and Telenta, B.: Numerical simulation of propagation of air pollution released from coal power plant during snowstorm, 13th Int. Conf. on Clouds and Prec. Reno, Nevada $30 \quad$ USA. Proc., I, 902-905, 2000.

Taylor, G. R.: Sulfate production and deposition in midlatitude continental cumulus clouds I, Cloud model formulation and base run analysis, J. Atmos. Sci., 46, 13, 1971-1990, 1989a.

Taylor, G. R.: Sulfate production and deposition in midlatitude continental cumulus clouds II,

\section{ACPD}

2, 385-430, 2002

\section{Impact of a deep convection on sulfate transport}

V. Spiridonov and M. Ćurić

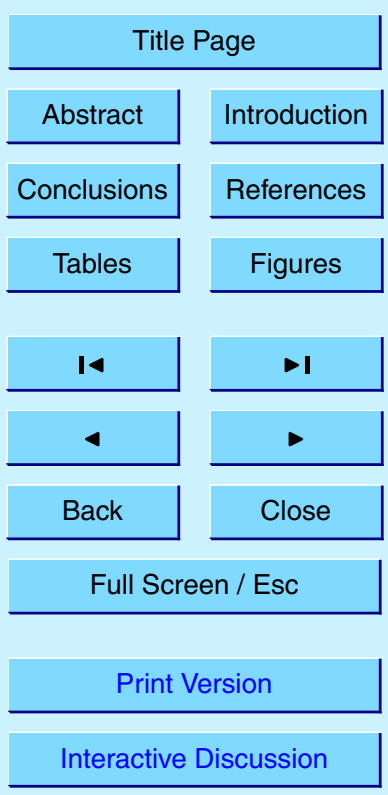

(C) EGS 2002 
Chemistry model formulation and sensitivity analysis, J. Atmos. Sci., 46, 13, 1991-2007, 1989b.

Telenta, B. and Aleksic, N.: A three-dimensional simulation of the 17 June 1978 HIPLEX case with observed ice multiplication, 2nd Int. Cloud Modeling Workshop, Toulouse, WMO/TD-No.

5 268, 277-285, 1988.

Tremblay, A. and Leighton, H.: A three-dimensional cloud chemistry model, J. Climate Appl. Meteor., 25, 652-671, 1986.

Walcek, C. J. and Taylor, G. R.: A theoretical method for computing vertical distributions of acidity and sulfate production within cumulus clouds, J. Atmos. Sci, 43, 4, 339-355, 1986.

Wang, C. and Chang, J. S.: A three-dimensional numerical model of cloud dynamics, microphysics and chemistry, 4. Cloud chemistry and precipitation chemistry, J. Geophys. Res., 98, 16799-16808, 1993a.

Wang, C. and Chang, J. S.: A three-dimensional numerical model of cloud dynamics, microphysics, and chemistry, 1. Concepts and formulation, J. Geophys. Res., 98, 14 827-17844, 1993b.

Wang, C. and Prinn, R. G.: On the roles of deep convective clouds in tropospheric chemistry, J. Geophys. Res., 105, 22 269-22 297, 2000.

Yin, Y. Parker, D. J., and Carslaw, K. S.: Simulation of trace gas redistribution by convective clouds-Liqiid phase processes, Atmos. Chem. Phys., 1, 19-36, 2001.

\section{Impact of a deep convection on sulfate transport}

V. Spiridonov and M. Ćurić

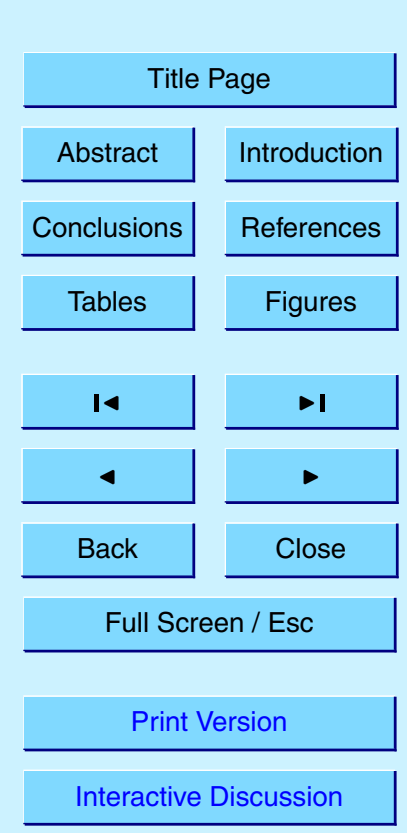




\section{ACPD}

$2,385-430,2002$

Table 1. List of authors with brief description of cloud-chemistry models used in their studies

\begin{tabular}{|c|c|c|c|c|c|c|c|}
\hline $\begin{array}{l}\text { Authors of sep- } \\
\text { arate studies }\end{array}$ & $\begin{array}{l}\text { Taylor (1989a, } \\
\text { b) }\end{array}$ & $\begin{array}{l}\text { Tremblay and } \\
\text { Leighton (1986) }\end{array}$ & $\begin{array}{l}\text { Wang and } \\
\text { Chang (1993b) }\end{array}$ & $\begin{array}{l}\text { Crutzen and } \\
\text { Lawrence } \\
(2000)\end{array}$ & $\begin{array}{ll}\text { Barth } & \text { et } \\
\text { al. }(2001) & \end{array}$ & Yin et al. (2001) & $\begin{array}{l}\text { Spiridonov and } \\
\text { Curić(2002) }\end{array}$ \\
\hline $\begin{array}{l}\text { The basic char- } \\
\text { acteristic of the } \\
\text { model }\end{array}$ & $\begin{array}{l}\text { 1-D dimen- } \\
\text { sional cumulus } \\
\text { cloud model }\end{array}$ & $\begin{array}{l}\text { 3-D (warm } \\
\text { cumulus cloud } \\
\text { model) }\end{array}$ & $\begin{array}{l}\text { 3-D non- } \\
\text { hydrostatic } \\
\text { cloud model }\end{array}$ & $\begin{array}{lr}3-D \quad \text { global } \\
\text { model (MATCH) }\end{array}$ & $\begin{array}{l}\text { 3-D non- } \\
\text { hydrostatic } \\
\text { cloud model }\end{array}$ & $\begin{array}{l}2-D \quad \text { non- } \\
\text { hydrostatic } \\
\text { cloud model }\end{array}$ & $\begin{array}{l}\text { 3-D non- } \\
\text { hydrostaic } \\
\text { cloud model }\end{array}$ \\
\hline $\begin{array}{l}\text { Model dy- } \\
\text { namics and } \\
\text { thermodynam- } \\
\text { ics }\end{array}$ & $\begin{array}{l}1.5 \mathrm{D} \text { Eulerian } \\
\text { model cloud } \\
\text { TKE Local tur- } \\
\text { bulent Kinetic } \\
\text { energy }\end{array}$ & $\begin{array}{l}\text { Compressible } \\
\text { Cloud model }\end{array}$ & $\begin{array}{l}\text { Compressible } \\
\text { cloud model } \\
\text { Ice-liquid poten- } \\
\text { tial temperature } \\
\text { 1-order closure } \\
\text { scheme }\end{array}$ & $\begin{array}{l}\text { Global model } \\
\text { for chemical } \\
\text { transport }\end{array}$ & $\begin{array}{l}\text { Compressible } \\
\text { cloud model }\end{array}$ & Slab-symmetric & $\begin{array}{l}\text { Compressible } \\
\text { cloud model } 1.5 \\
\text { TKE closure } \\
\text { scheme Prog- } \\
\text { nostic equation } \\
\text { for entropy }\end{array}$ \\
\hline $\begin{array}{l}\text { Model micro- } \\
\text { physics }\end{array}$ & $\begin{array}{l}\text { Bulk-water } \\
\text { microphysics }\end{array}$ & $\begin{array}{l}\text { A simply bulk- } \\
\text { parameterization } \\
\text { warm micro- } \\
\text { physics }\end{array}$ & $\begin{array}{l}\text { Semi-spectral } \\
\text { microphysics } \\
\text { scheme }\end{array}$ & & $\begin{array}{l}\text { Mixed phase } \\
\text { Particle micro- } \\
\text { physics }\end{array}$ & $\begin{array}{l}\text { Detail mi- } \\
\text { crophysics. } \\
\text { Method of } \\
\text { Multimoments }\end{array}$ & $\begin{array}{l}\text { Bulk-water pa- } \\
\text { rameterization } \\
\text { with significant } \\
\text { improvements }\end{array}$ \\
\hline $\begin{array}{l}\text { Model chem- } \\
\text { istry }\end{array}$ & $\begin{array}{l}\text { Sulfate chem- } \\
\text { istry parameter- } \\
\text { ization }\end{array}$ & $\begin{array}{l}\text { Liquid-gas } \\
\text { phase chem- } \\
\text { istry }\end{array}$ & $\begin{array}{l}\text { Gas phase and } \\
\text { liquid-ice phase } \\
\text { chemical reac- } \\
\text { tions }\end{array}$ & $\begin{array}{l}\text { Transport trace- } \\
\text { gases Scaveng- } \\
\text { ing and disso- } \\
\text { lution in liquid } \\
\text { phase }\end{array}$ & $\begin{array}{l}\text { Transport and } \\
\text { scavenging of } \\
\text { tracers (highly } \\
\text { soluble and } \\
\text { passive tracers) }\end{array}$ & $\begin{array}{l}\text { Spectral treat- } \\
\text { ment of scav- } \\
\text { enging and } \\
\text { redistribution of } \\
\text { gases (tracers) }\end{array}$ & $\begin{array}{l}\text { Liquid-ice } \\
\text { phase chemical } \\
\text { reactions (sul- } \\
\text { fate chemistry) } \\
\text { inside clouds }\end{array}$ \\
\hline
\end{tabular}

Impact of a deep convection on sulfate transport

V. Spiridonov and M. Ćurić

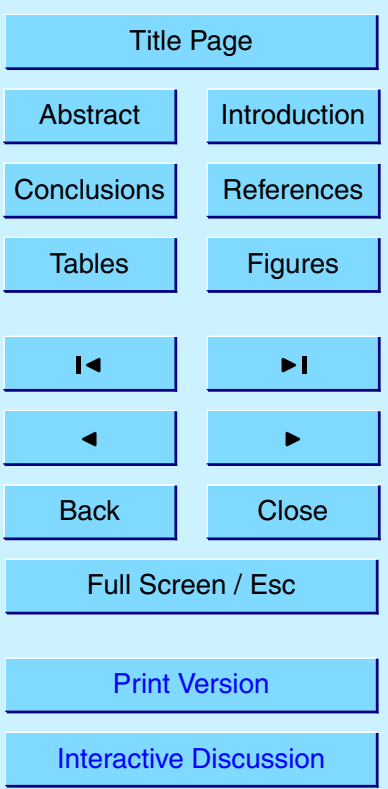




\section{ACPD}

Table 2. Equilibrium Reactions and rate coefficients

\begin{tabular}{ccccc}
\hline$N_{0}$ & Reactions & $K_{298}\left(\mathrm{M} \mathrm{or} \mathrm{M} \mathrm{atm}^{-1}\right.$ & $-H_{298} / R(K)$ & References $^{*}$ \\
\hline 1 & $\mathrm{SO}_{2}(\mathrm{~g}) \Leftrightarrow \mathrm{SO}_{2}(\mathrm{ag})$ & 1.2 & 3135. & $(1)$ \\
2 & $\mathrm{SO}_{2}(\mathrm{aq}) \Leftrightarrow \mathrm{HSO}_{3}^{-}+\mathrm{H}^{+}$ & $1.3 \times 10^{-2}$ & 2000. & $(2)$ \\
3 & $\mathrm{HSO}_{3}^{-} \Leftrightarrow \mathrm{SO}_{3}^{-2}+\mathrm{H}^{+}$ & $6.3 \times 10^{-8}$ & 1495. & $(3)$ \\
4 & $\mathrm{O}_{3}(\mathrm{~g}) \Leftrightarrow \mathrm{O}_{3}(\mathrm{aq})$ & $1.13 \times 10^{-2}$ & 2300. & $(4)$ \\
5 & $\mathrm{H}_{2} \mathrm{O}_{2}(\mathrm{~g}) \Leftrightarrow \mathrm{H}_{2} \mathrm{O}_{2}(\mathrm{aq})$ & $7.1 \times 10^{4}$ & 6800. & $(5)$ \\
6 & $\mathrm{NH}_{3}(\mathrm{~g}) \Leftrightarrow \mathrm{NH}_{4} \mathrm{OH}(\mathrm{aq})$ & 75 & 3400. & $(6)$ \\
7 & $\mathrm{HNO}_{3}(\mathrm{~g}) \Leftrightarrow \mathrm{HNO}_{3}(\mathrm{aq})$ & $2.1 \times 10^{5}$ & 8700. & $(7)$ \\
8 & $\mathrm{CO}_{2}(\mathrm{~g}) \Leftrightarrow \mathrm{CO}_{2}(\mathrm{aq})$ & $3.4 \times 10^{-2}$ & 2420. & $(8)$ \\
\hline
\end{tabular}

$2,385-430,2002$

\section{Impact of a deep convection on sulfate transport}

V. Spiridonov and M. Ćurić

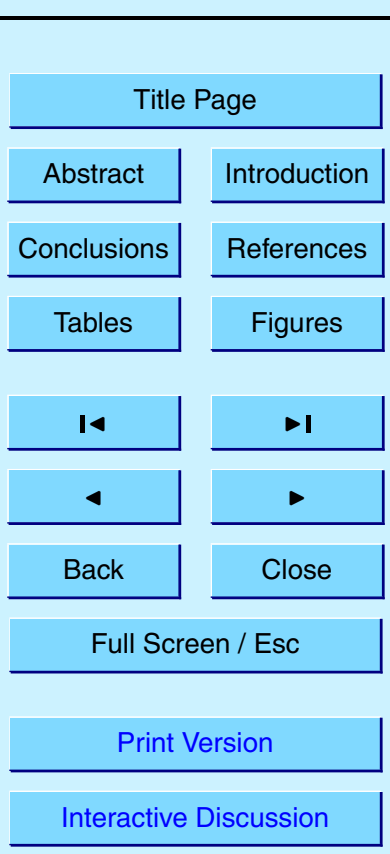

* (1), (2), (3) are derived from values given in Hoffmann and Calvert (1985); (4), (6) and (8) Pandis and Seinfeld (1989); (5) Martin and Damaschen (1981) and (7) Schwartz and White (1981)

(C) EGS 2002 


\section{ACPD}

2, 385-430, 2002

\section{Impact of a deep convection on sulfate transport}

V. Spiridonov and M. Ćurić

Table 3. S (IV) Oxidation's and the corresponding coefficients

\begin{tabular}{ccccc}
\hline$N_{0}$ & Reaction & $K_{298}\left(\mathrm{M}^{n} \mathrm{~s}^{-1}\right)$ & $-\Delta H / R(\mathrm{~K})$ & References $^{*}$ \\
\hline 9 & $\mathrm{~S}(\mathrm{IV})+\mathrm{O}_{3} \rightarrow \mathrm{S}(\mathrm{IV})+\mathrm{O}_{2}$ & $3.7 \times 10^{+5}$ & 5530 & $(9)$ \\
10 & $\mathrm{~S}(\mathrm{IV})+\mathrm{H}_{2} \mathrm{O}_{2} \rightarrow \mathrm{S}(\mathrm{IV})+\mathrm{H}_{2} \mathrm{O}$ & $7.45 \times 10^{+7}$ & 4751 & (10) \\
\hline
\end{tabular}

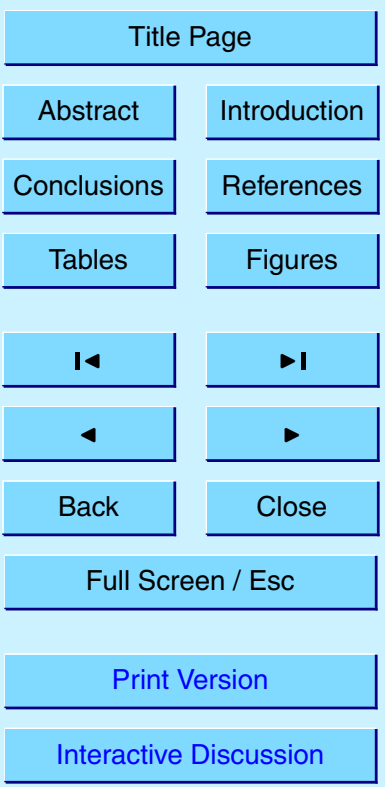




\section{ACPD}

$2,385-430,2002$

Table 4. Initial fields of chemical species including in sulfate production for continental nonpolluted and continental polluted background - Taylor (1989b)

Chemical species expressed through mixing ratios

Continental non-polluted clouds

$$
q_{i}(0)\left[\mu \mathrm{g} \mathrm{kg}^{-1}\right. \text { (air)] }
$$

$\mathrm{H}(\mathrm{km})$

$q_{\mathrm{SO}_{2}}$
$q_{\mathrm{SO}_{4}^{-2}}$
$q_{\mathrm{NH}_{4}^{+}}$
$q_{\mathrm{H}_{2} \mathrm{O}_{2}}$
$q_{\mathrm{O}_{3}}$

4.42
3.1
0.58
0.59
82.8

3.1

0.58

0.59

82.8

21.0

16.0

3.0

0.59

82.2

2.0

3.5

3.5

$\propto$

$\propto$

\section{Impact of a deep convection on sulfate transport}

V. Spiridonov and M. Ćurić

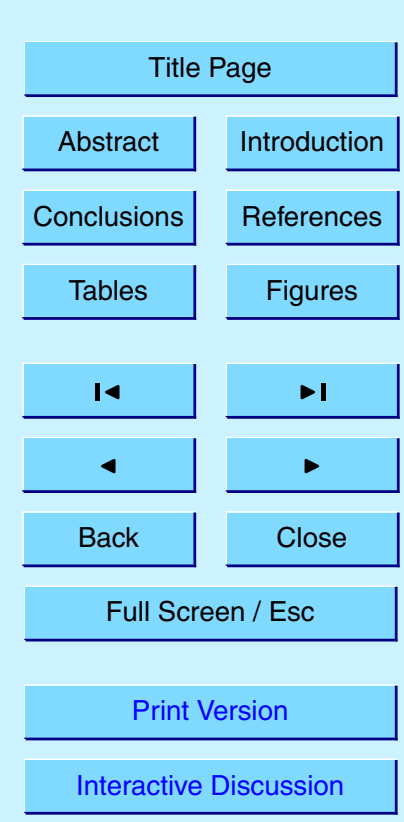

(C) EGS 2002 


\section{ACPD}

$2,385-430,2002$

\section{Impact of a deep convection on sulfate transport}

V. Spiridonov and M. Ćurić

Table 5. The comparison between simulated and observed parameters on 6 July 1995 (Summer Case)

\begin{tabular}{lllllll}
\hline Parameter & $\begin{array}{l}\text { Cloud base } \\
(\mathrm{km})\end{array}$ & $\begin{array}{l}\text { Cloud top } \\
(\mathrm{km})\end{array}$ & $\begin{array}{l}\text { Max. vertical } \\
\text { velocity } \\
(\mathrm{m} / \mathrm{s})\end{array}$ & $\begin{array}{l}\text { Max. radar } \\
\text { reflectivity } \\
(\mathrm{dBz})\end{array}$ & $\begin{array}{l}\text { Total } \\
\text { acc. rain } \\
\left(\mathrm{kg} / \mathrm{m}^{2}\right)\end{array}$ & $\begin{array}{l}\text { Total } \\
\text { acc. hail } \\
\left(\mathrm{kg} / \mathrm{m}^{2}\right)\end{array}$ \\
\hline Model & 2.2 & 13.5 & 20.4 & 56 & 175 & 1.3 \\
Observed & 2.4 & 14.6 & 18.3 & 50 & 180 & - \\
\hline
\end{tabular}

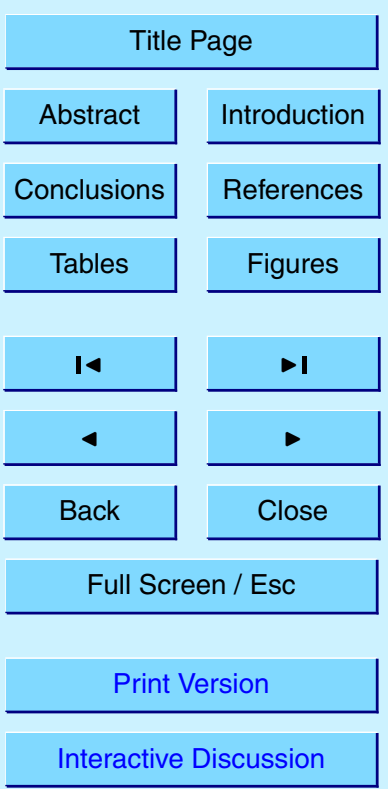




\section{ACPD}

Table 6. Parameters of numerical experiment on 3 April 2000. Values of parameters delineate in borders represent smoothed values

\begin{tabular}{|c|c|c|c|c|c|c|}
\hline \multirow[b]{2}{*}{ Parameter } & \multicolumn{6}{|c|}{ Time } \\
\hline & $10 \mathrm{~min}$ & $20 \mathrm{~min}$ & $30 \mathrm{~min}$ & $40 \mathrm{~min}$ & $50 \mathrm{~min}$ & $60 \mathrm{~min}$ \\
\hline Total rainfall $\left(1 / \mathrm{m}^{2}\right)$ & 0.0 & 0.0 & 5.6 & 19.5 & 24.3 & 27.8 \\
\hline $\mathrm{pH}$-cloud water & $\begin{array}{l}5.1 \\
(5.0)\end{array}$ & $\begin{array}{l}6.3 \\
(6.0)\end{array}$ & $\begin{array}{l}7.0 \\
(6.5)\end{array}$ & $\begin{array}{l}8.1 \\
(6.0)\end{array}$ & $\begin{array}{l}7.0 \\
(5.0)\end{array}$ & $\begin{array}{l}7.0 \\
(5.5)\end{array}$ \\
\hline $\mathrm{pH}$ - rain & $\begin{array}{l}3.0 \\
(3.0)\end{array}$ & $\begin{array}{c}4.7 \\
(4.5)\end{array}$ & $\begin{array}{l}7.7 \\
(7.0)\end{array}$ & $\begin{array}{l}7.0 \\
(3.6)\end{array}$ & $\begin{array}{c}7.0 \\
(4.5)\end{array}$ & $\begin{array}{l}7.0 \\
(5.5)\end{array}$ \\
\hline $\begin{array}{l}\text { Total wet deposition } \\
{\left[\mathrm{SO}_{4}^{2-}-\mathrm{S}\right]\left(\mathrm{mg} / \mathrm{m}^{2}\right)}\end{array}$ & 0.00 & 0.21 & 15.38 & 29.41 & 38.43 & 40.16 \\
\hline $\begin{array}{l}\text { Max. concentration } \\
{\left[\mathrm{SO}_{4}^{2-}-\mathrm{S}\right]\left(\mu \mathrm{g} / \mathrm{m}^{3}\right)}\end{array}$ & $\begin{array}{c}4.28 \\
(4.30)\end{array}$ & $\begin{array}{c}7.99 \\
(6.50)\end{array}$ & $\begin{array}{l}8.45 \\
(8.00)\end{array}$ & $\begin{array}{c}11.85 \\
(\mathbf{1 0 . 5 0 )}\end{array}$ & $\begin{array}{l}9.55 \\
(8.00)\end{array}$ & $\begin{array}{c}9.69 \\
(5.50)\end{array}$ \\
\hline $\begin{array}{l}\text { Total wet deposition } \\
{\left[\mathrm{SO}_{4}^{2-}-\mathrm{S}\right]\left(\mathrm{mg} / \mathrm{m}^{2}\right)}\end{array}$ & 0.00 & 0.21 & 15.38 & 29.41 & 38.43 & 40.16 \\
\hline $\begin{array}{l}\text { Max. ionic concentration }\left(\mu \mathrm{g} / \mathrm{m}^{3}\right) \\
{\left[\mathrm{NH}_{4}^{+}\right]}\end{array}$ & $\begin{array}{l}0.58 \\
(0.55)\end{array}$ & $\begin{array}{c}0.60 \\
(0.55)\end{array}$ & $\begin{array}{l}0.60 \\
(0.55)\end{array}$ & $\begin{array}{c}0.61 \\
(0.55)\end{array}$ & $\begin{array}{c}0.57 \\
(0.50)\end{array}$ & $\begin{array}{c}0.56 \\
(0.45)\end{array}$ \\
\hline $\begin{array}{l}\text { Mixing ratio of rain } \\
q_{R}(\mathrm{~g} / \mathrm{kg})\end{array}$ & 0.0 & 0.1 & 0.4 & 0.4 & 0.4 & 0.4 \\
\hline $\begin{array}{l}\text { Mixing ratio of snow } \\
q_{S}(\mathrm{~g} / \mathrm{kg})\end{array}$ & 0.0 & 0.6 & 1.5 & 1.5 & 1.5 & 1.5 \\
\hline $\begin{array}{l}\text { Max. vertical velocity } \\
\text { Wmax }(\mathrm{m} / \mathrm{s})\end{array}$ & 11.6 & 12.8 & 13.9 & 13.9 & 13.9 & 13.9 \\
\hline
\end{tabular}

$2,385-430,2002$

Impact of a deep convection on sulfate transport

V. Spiridonov and M. Ćurić

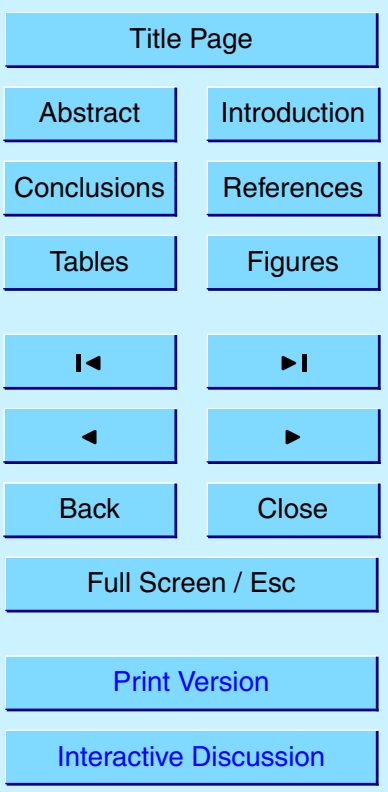




\section{ACPD}

Table 7. List of relevant parameters and relative contribution for sulfate deposition for continental and polluted background for a Summer Case simulation. Asterisk represents the regime of the model run

\begin{tabular}{|c|c|c|c|c|c|c|}
\hline $\begin{array}{l}\text { 2-D Model } \\
\text { Run }\end{array}$ & $\begin{array}{l}\text { Method of ki- } \\
\text { netic gas up- } \\
\text { take }\end{array}$ & $\begin{array}{l}\text { Henry's law } \\
\text { equilibrium }\end{array}$ & $\begin{array}{l}\text { Nucleation } \\
\text { and } \\
\text { dynamic- } \\
\text { impact } \\
\text { scavenging }\end{array}$ & $\begin{array}{l}\text { Liquid-ice } \\
\text { phase oxida- } \\
\text { tion of }\left(\mathrm{SO}_{2}\right) \\
\text { by } \mathrm{H}_{2} \mathrm{O}_{2} \text { and } \\
\mathrm{O}_{3}\end{array}$ & $\begin{array}{l}\text { Liquid-ice } \\
\text { phase pro- } \\
\text { cesses }\end{array}$ & $\begin{array}{l}\text { Continental/Polluted } \\
\text { (background) }\end{array}$ \\
\hline I & yes* & no & yes & yes & yes & 24.08 \\
\hline$\|$ & no & yes* & yes & yes & yes & 30.10 \\
\hline III & yes & no & no' & yes & yes & 18.26 \\
\hline IV & yes & no & yes & no' & yes & 18.60 \\
\hline V & yes & no & yes & yes & no' & 26.59 \\
\hline
\end{tabular}

$2,385-430,2002$

Impact of a deep convection on sulfate transport

V. Spiridonov and M. Ćurić

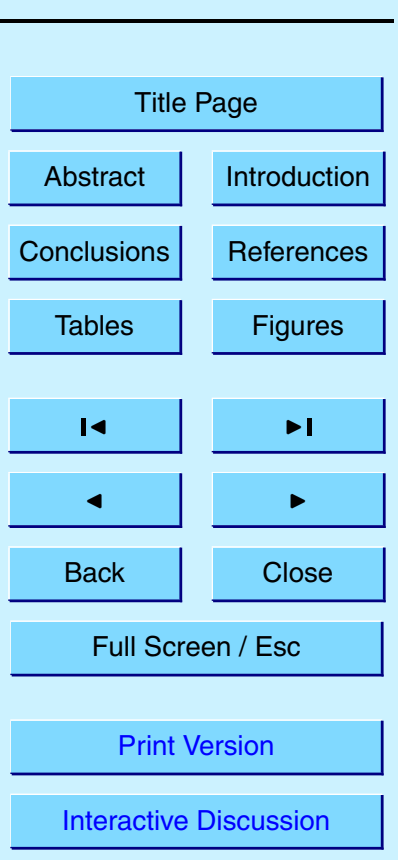




\section{ACPD}

2, 385-430, 2002

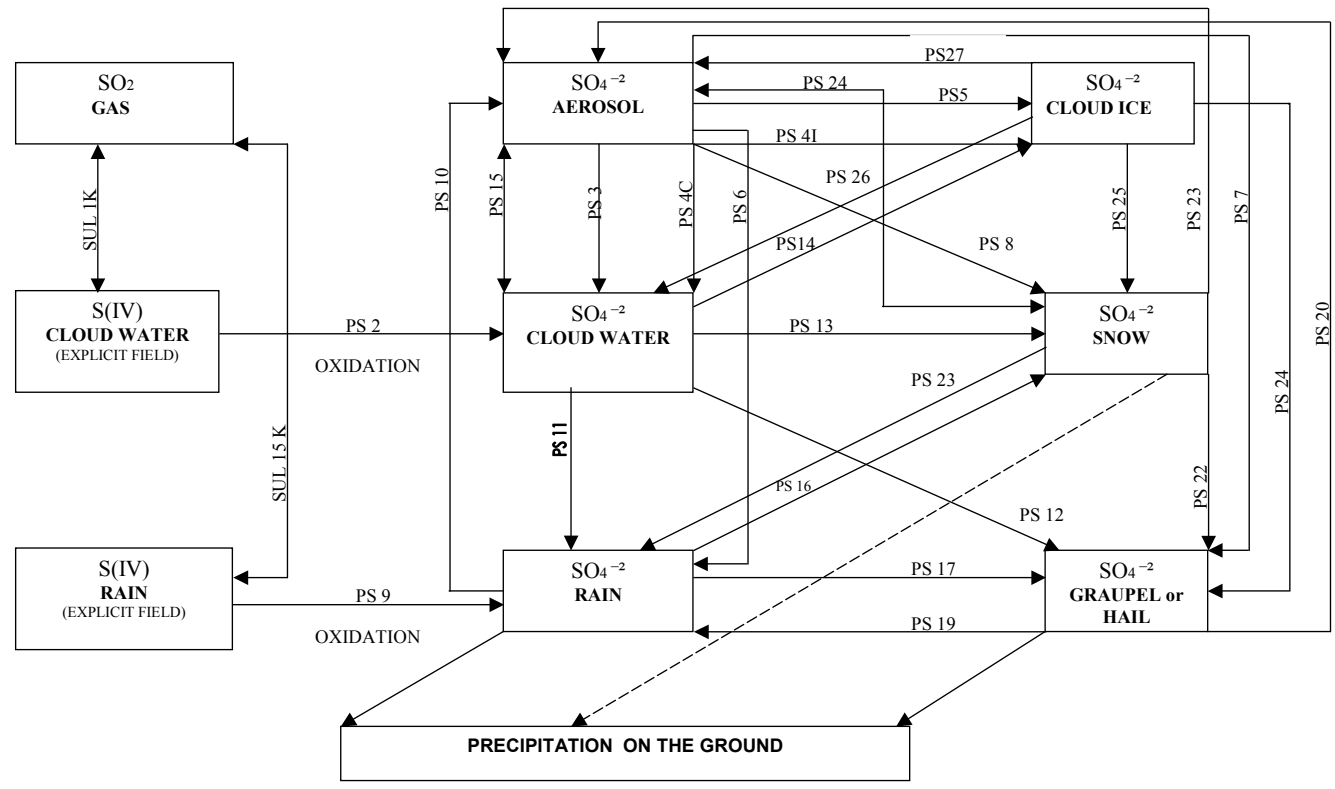

Fig. 1. Schematic of $\mathrm{SO}_{2}$ and $\mathrm{SO}_{4}^{-2}$ reactions with explicit treatment of $\mathrm{S}$ (IV) in cloud water and rainwater Taylor (1989b) and microphysical transitions according Lin et al. (1983).

\section{Impact of a deep convection on sulfate transport}

V. Spiridonov and M. Ćurić

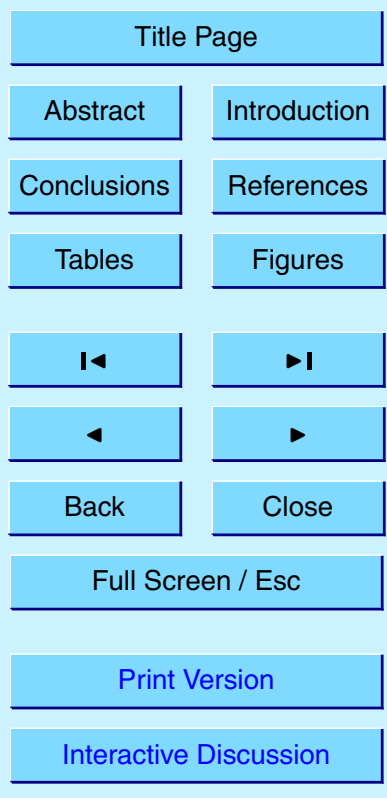




\section{ACPD}

2, 385-430, 2002

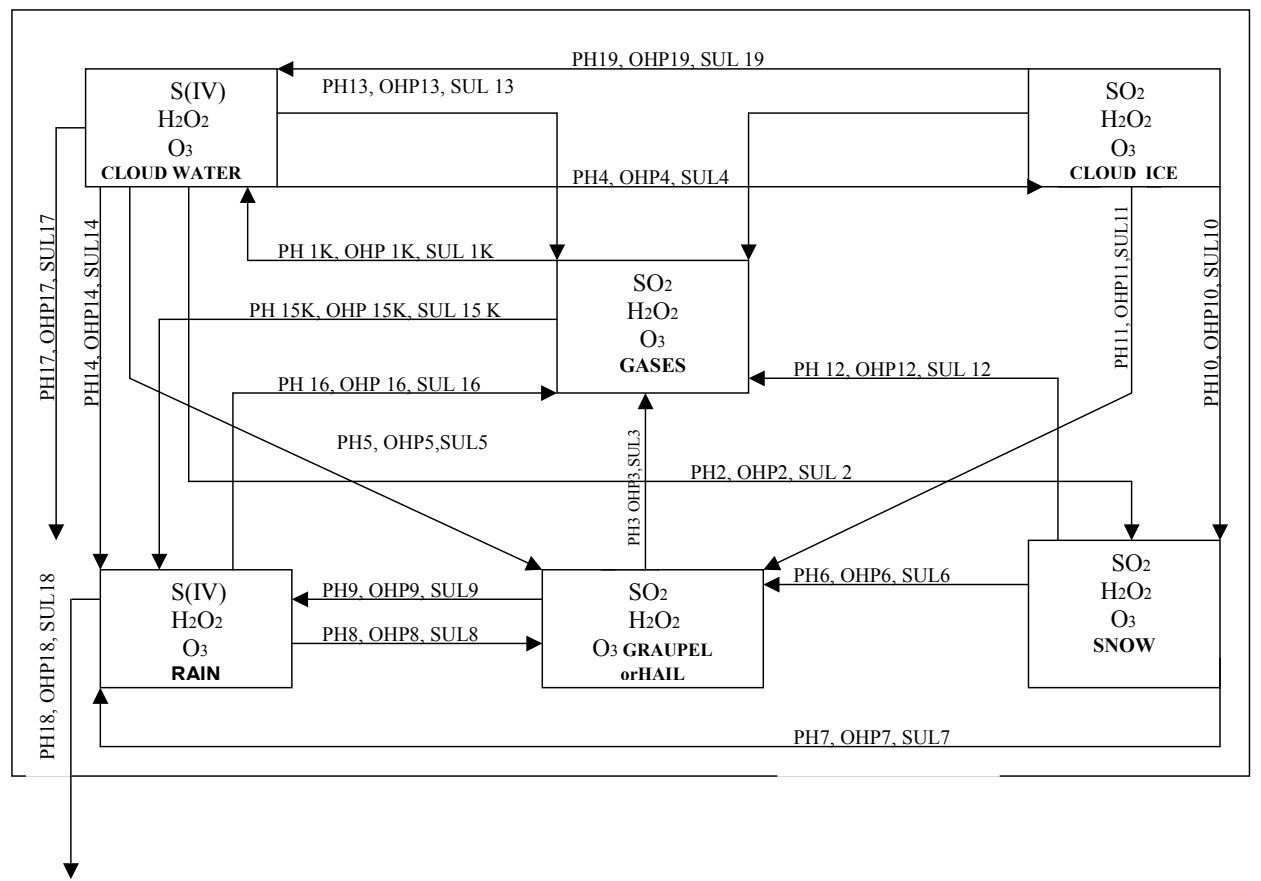

Impact of a deep convection on sulfate transport

V. Spiridonov and M. Ćurić

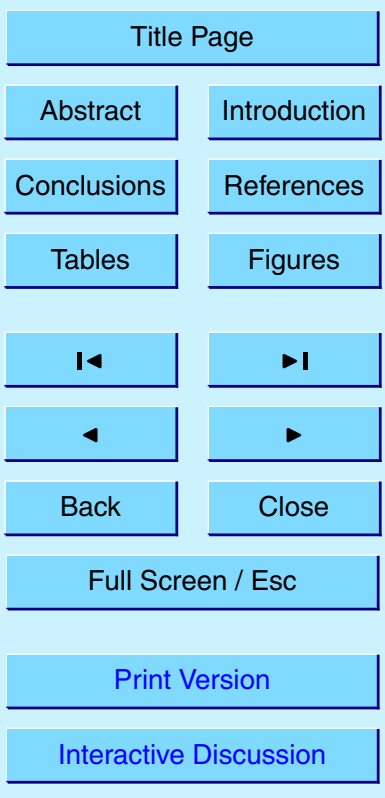

Fig. 2. Schematic of $\mathrm{H}_{2} \mathrm{O}_{2}, \mathrm{SO}_{2}$ and $\mathrm{O}_{3}$ reactions, Taylor (1989b) and microphysical transitions according Lin et al. (1983). 
Figt: The 00:00 GMT atm. sounding for Macedonia

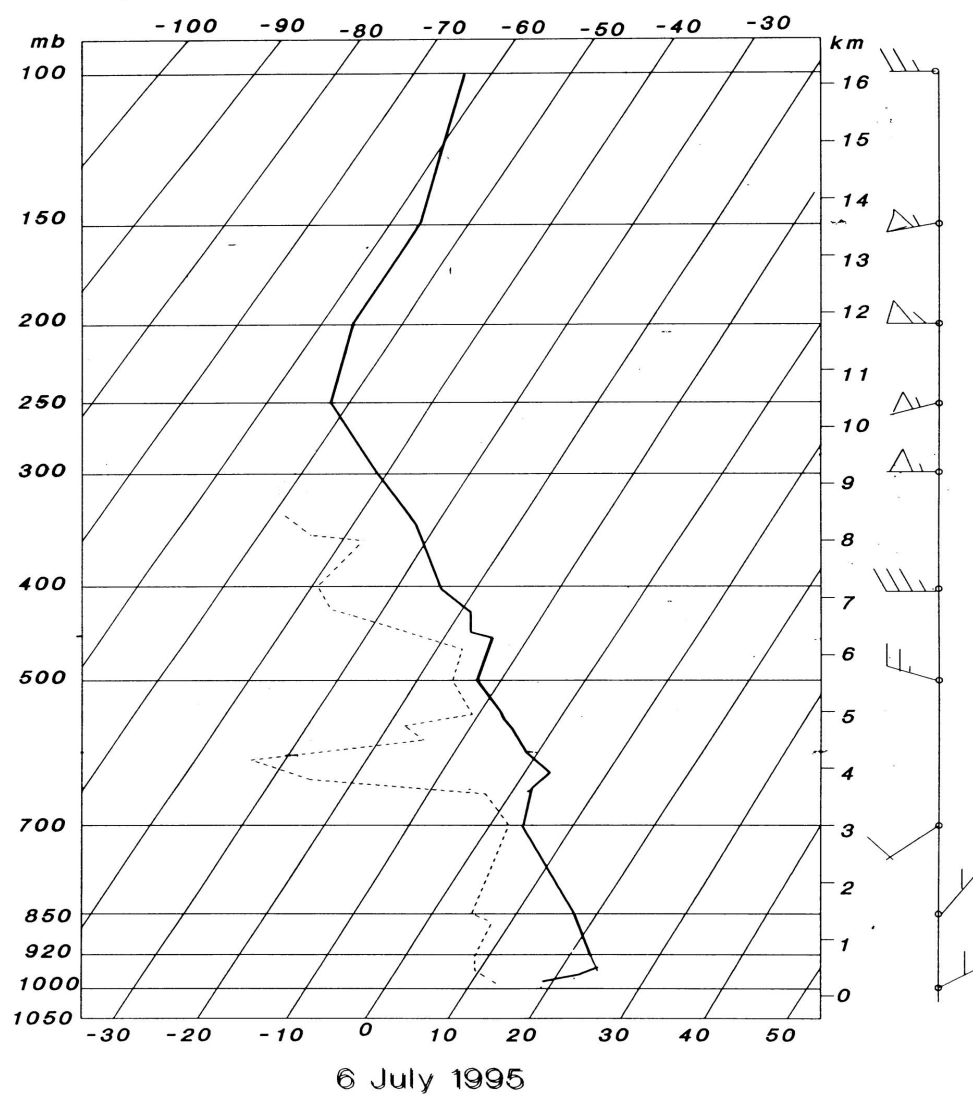

Fig. 3. The 00:00 GMT atmospheric sounding for Skopje, on 6 July 1995. Coordinate lines denote pressure $(\mathrm{hPa})$ and temperature $\left({ }^{\circ} \mathrm{C}\right)$. The solid line represents the temperature profile and the dashed line represents the moisture profile. Symbols on the r.h.s. of the same figure denote wind profile (direction and velocity).

\section{ACPD}

2, 385-430, 2002

\section{Impact of a deep convection on sulfate transport}

V. Spiridonov and M. Ćurić

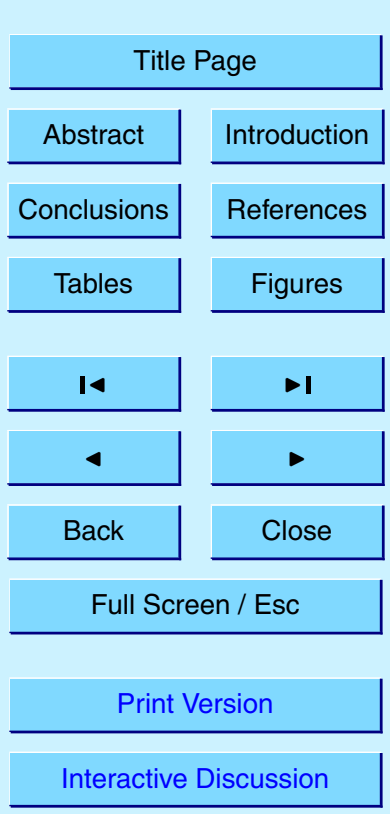

(C) EGS 2002 

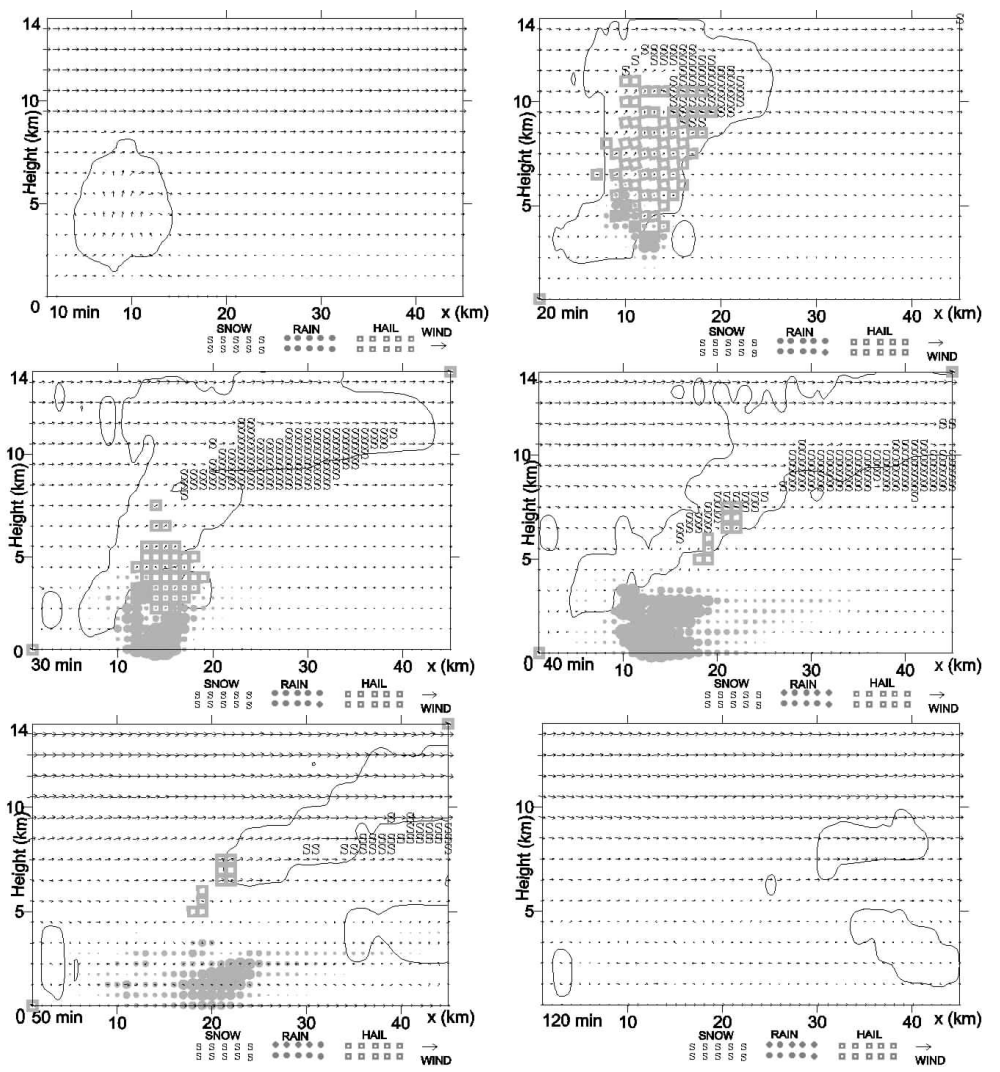

ACPD

2, 385-430, 2002

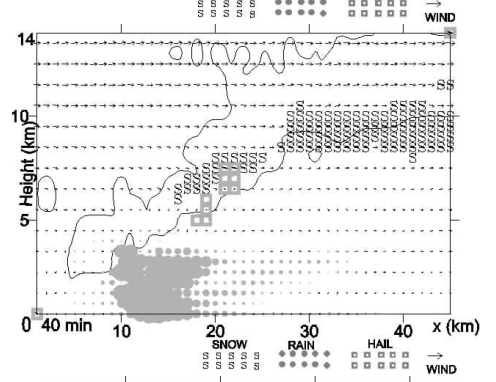

V. Spiridonov and

M. Ćurić

\section{transport \\ Impact of a deep convection on sulfate}
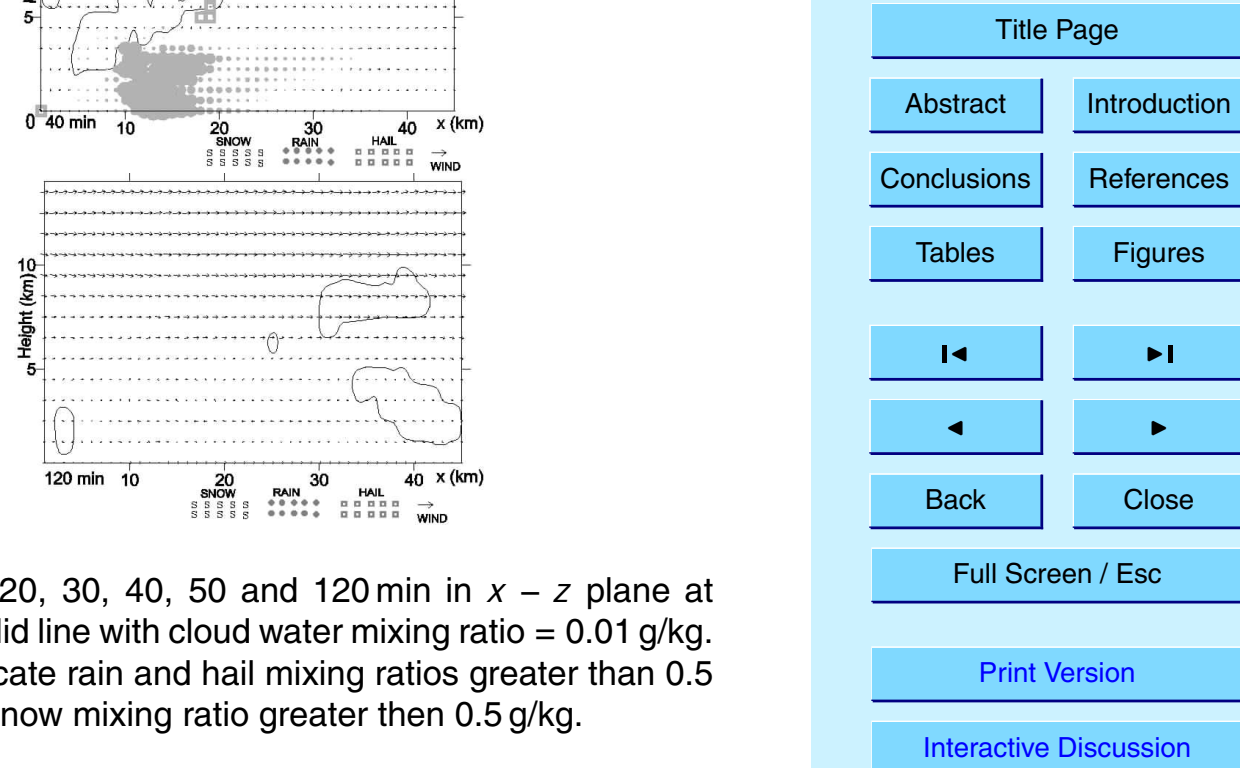

Fig. 4. The general cloud appearance at 10, 20, 30, 40, 50 and $120 \mathrm{~min}$ in $x-z$ plane at $y=8.0 \mathrm{~km}$. Cloudy areas are outlined by the solid line with cloud water mixing ratio $=0.01 \mathrm{~g} / \mathrm{kg}$. The arrows denote wind, dots and asteriks indicate rain and hail mixing ratios greater than 0.5 $\mathrm{g} / \mathrm{kg}$, respectively. The symbol ' $s$ ' denotes the snow mixing ratio greater then $0.5 \mathrm{~g} / \mathrm{kg}$.

Interactive Discussion 


\section{ACPD}
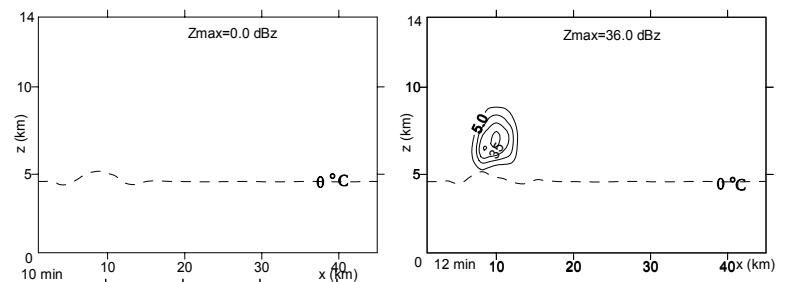

2, 385-430, 2002
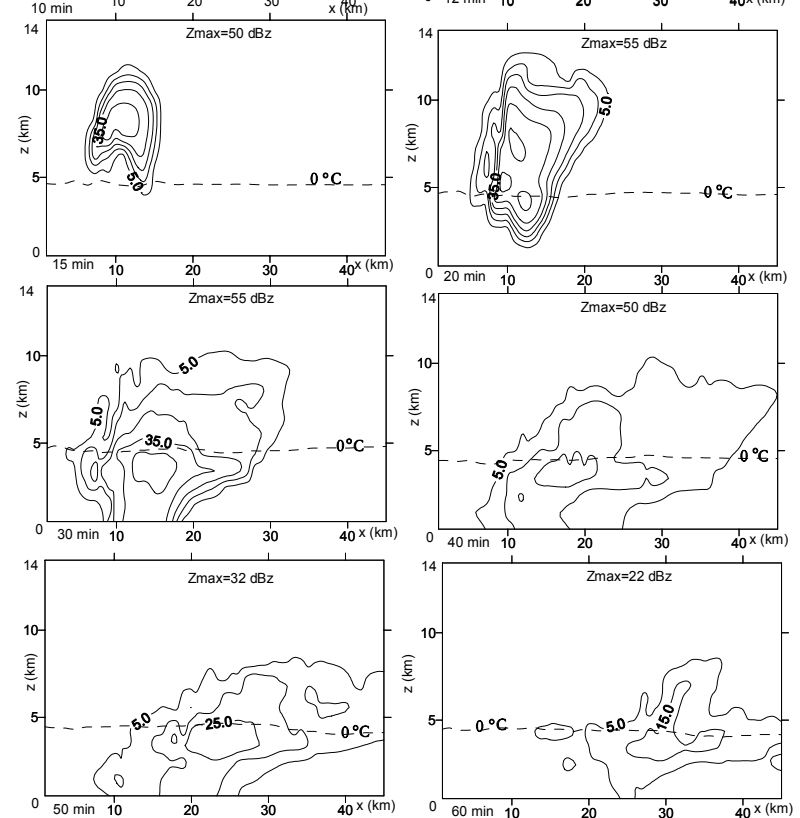

Fig. 5. The radar reflectivity history maps $(\mathrm{dBz})$ in $x-z$ plane at $y=8.0 \mathrm{~km}$ at $10,12,15,20$, $30,40,50$ and $60 \mathrm{~min}$. Dashed lines denote $\left({ }^{\circ} \mathrm{C}\right)$ isotherm.

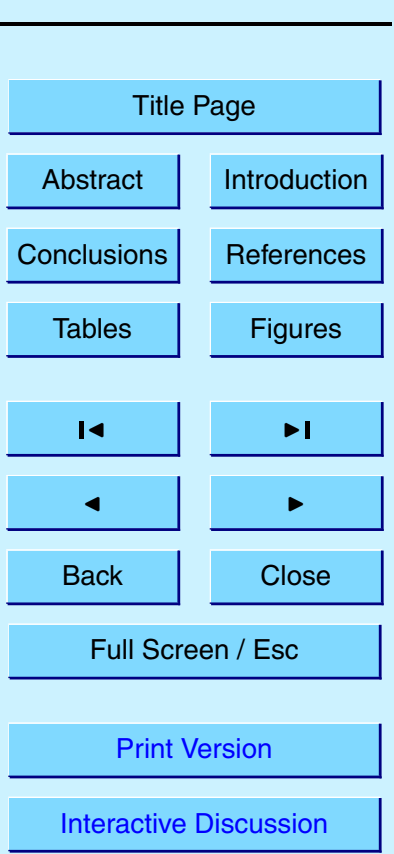

Interactive Discussion

(C) EGS 2002

Impact of a deep convection on sulfate transport

V. Spiridonov and M. Ćurić 

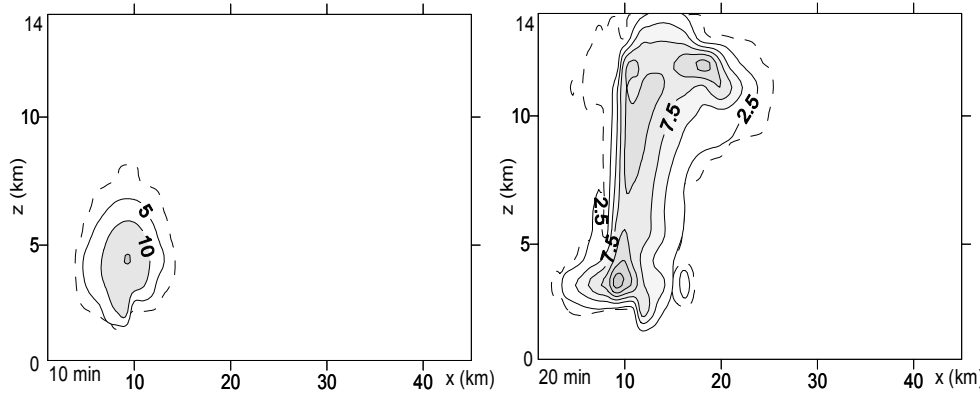

ACPD
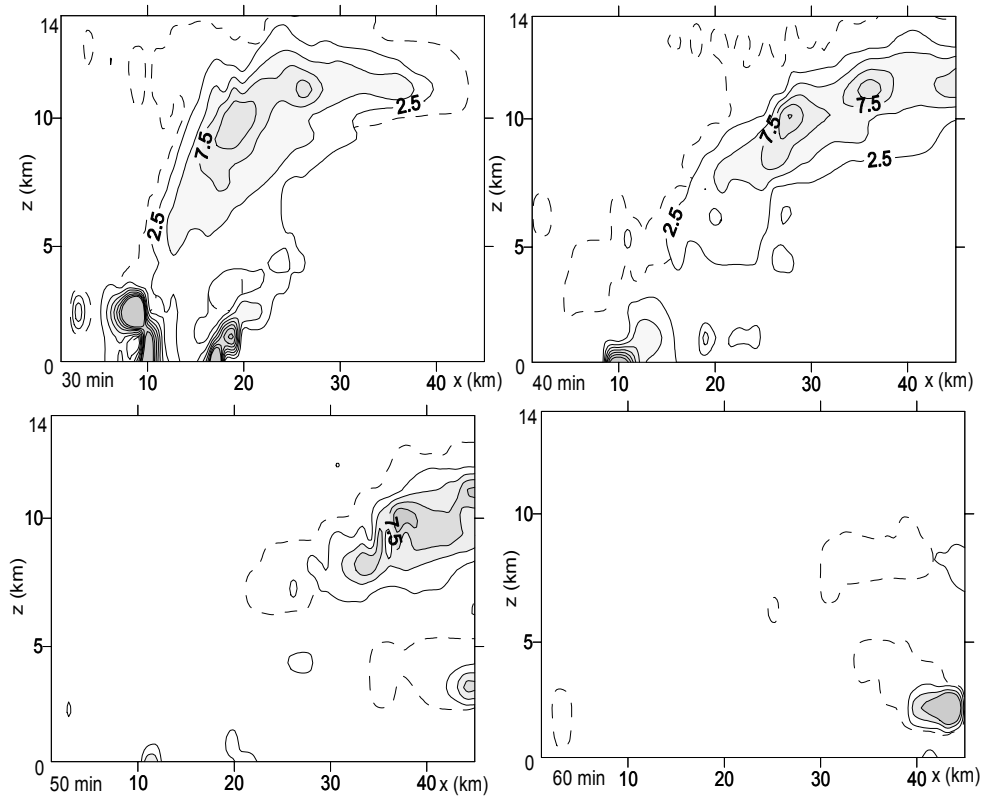

2, 385-430, 2002

\section{Impact of a deep convection on sulfate transport}

V. Spiridonov and M. Ćurić

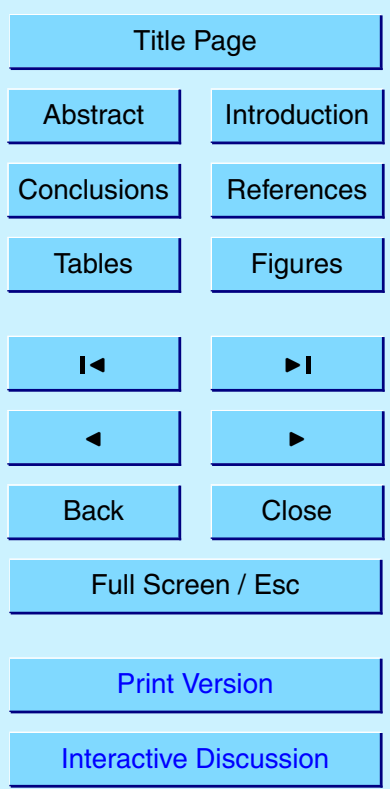

Fig. 6. Time evolution of sulfate concentration in the cloud $\left(\mu \mathrm{g} / \mathrm{m}^{3}\right)$ in $x-z$ plane at $y=8.0 \mathrm{~km}$. 


\section{ACPD}
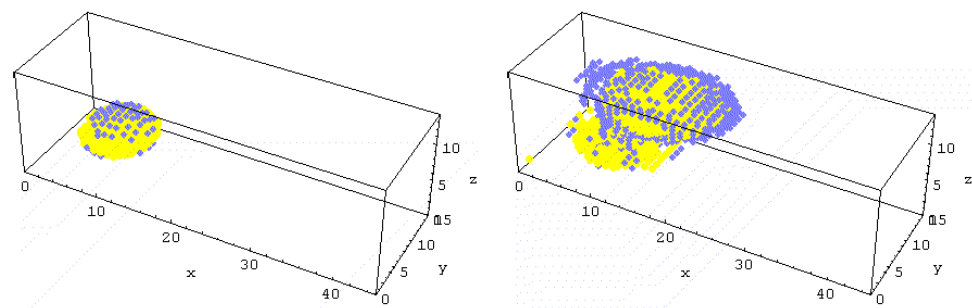

$2,385-430,2002$
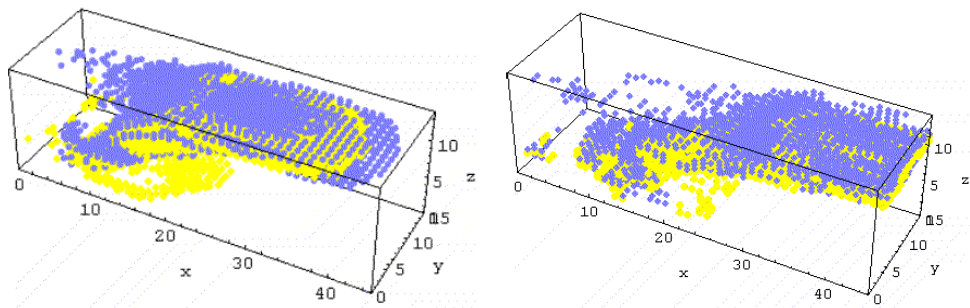

\section{Impact of a deep convection on sulfate transport}

V. Spiridonov and M. Ćurić
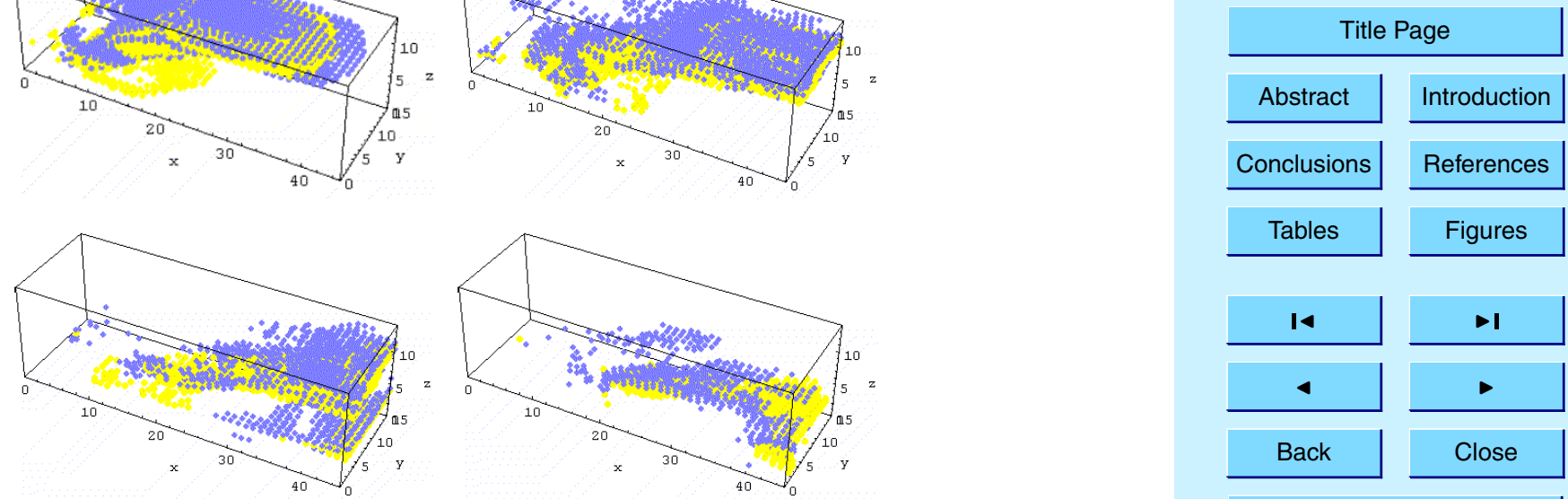

Fig. 7. Three-dimensional view of sulfate transport and redistribution, in 10, 20, 30, 40, 50 and $120 \mathrm{~min}$. Blue patterns delineate cloud water mixing ratio greater then $0.01 \mathrm{~g} / \mathrm{kg}$, yellow fields are sulfate concentrations greater than $2.5\left(\mu \mathrm{g} / \mathrm{m}^{3}\right)$.

\section{Full Screen / Esc}

\section{Print Version}

Interactive Discussion

(C) EGS 2002 

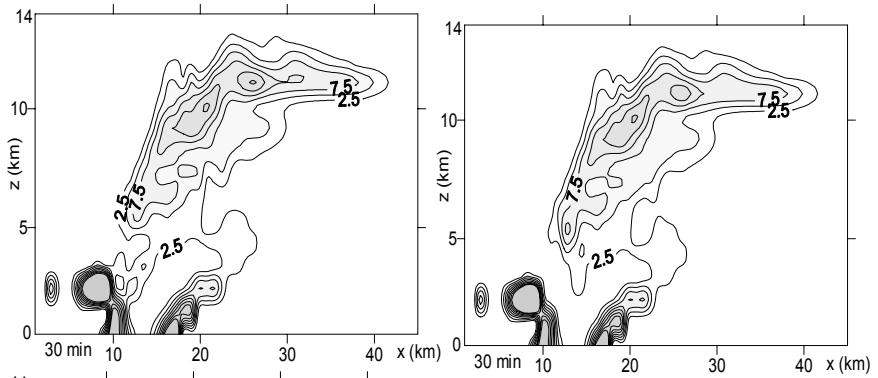

ACPD
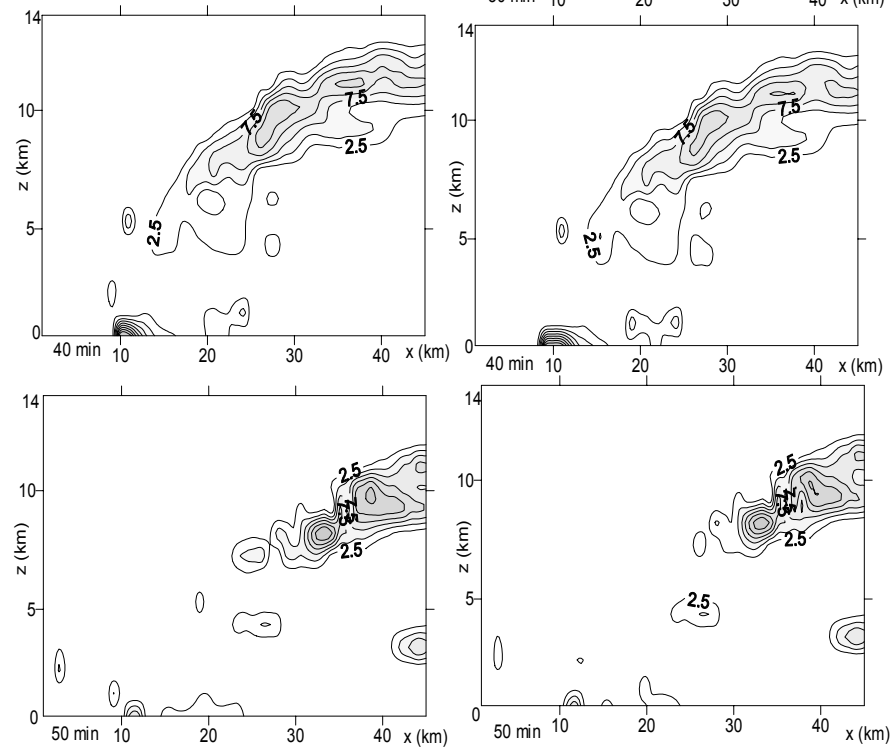

2, 385-430, 2002

\section{Impact of a deep convection on sulfate transport}

V. Spiridonov and M. Ćurić

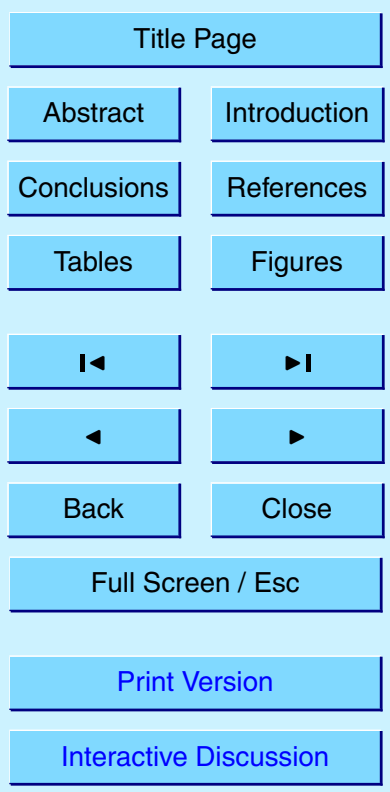

Fig. 8. Time evolution of the sulfate concentration $\left(\mu \mathrm{g} / \mathrm{m}^{3}\right)$ in the $x-z$ plane at $y=8.0 \mathrm{~km}$. Panels on the I.h.s. represent sulfate distribution by oxidation off run, those on the r.h.s. represent teractive Discussion distributions of oxidation on run. 

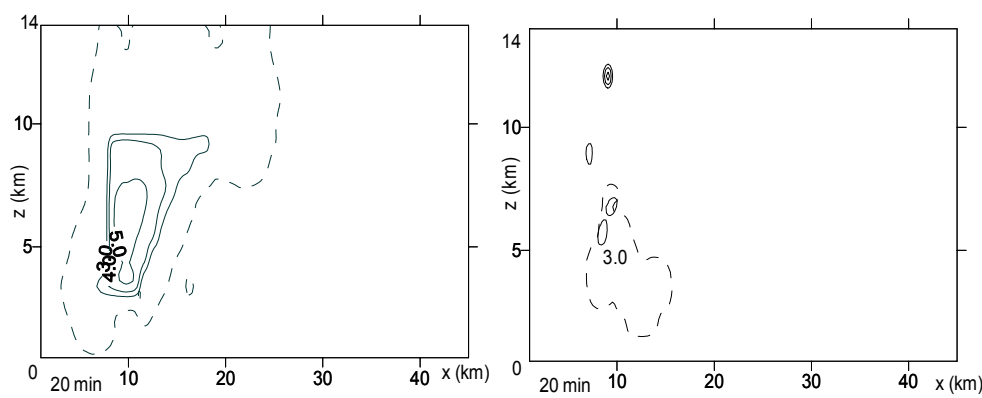

ACPD
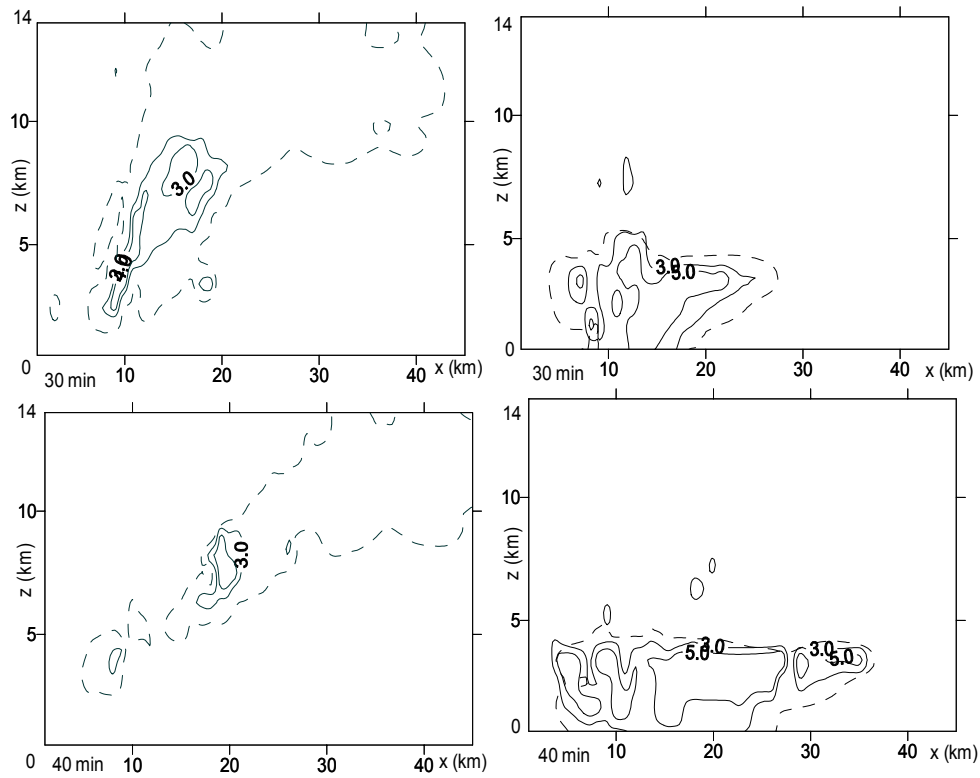

Fig. 9. Time evolution of the $\mathrm{pH}$ values of cloud water (I.h.s.) and rainwater (r.h.s.) in the $x-z$ plane at $y=8.0 \mathrm{~km}$.

$2,385-430,2002$

Impact of a deep convection on sulfate transport

V. Spiridonov and M. Ćurić

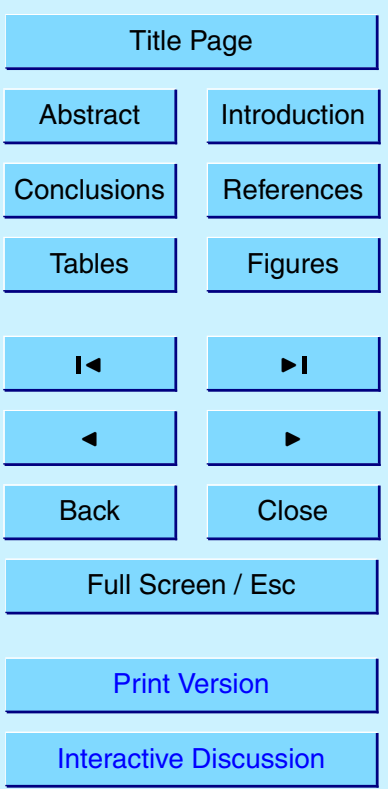



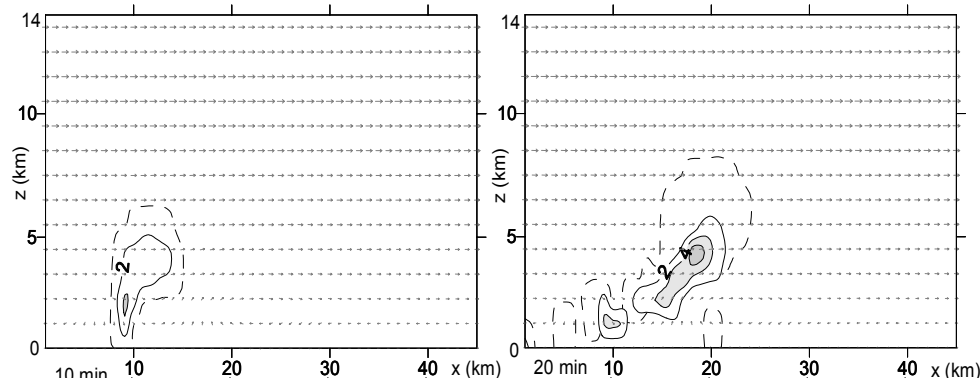

ACPD
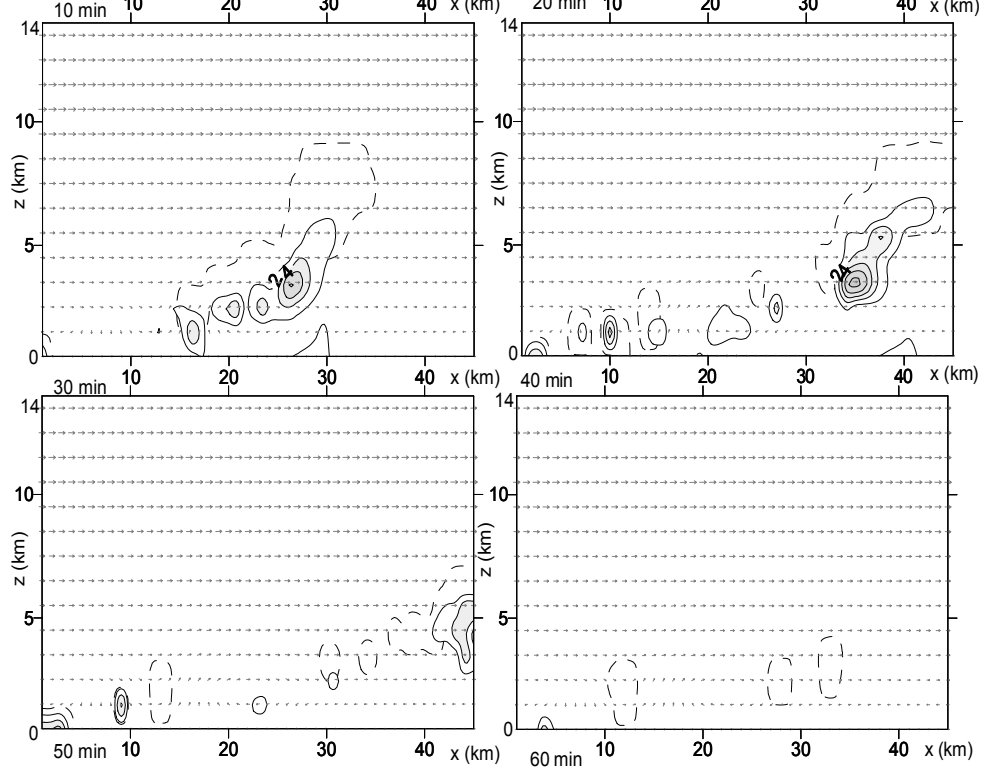

$2,385-430,2002$

\section{Impact of a deep convection on sulfate transport}

V. Spiridonov and M. Ćurić

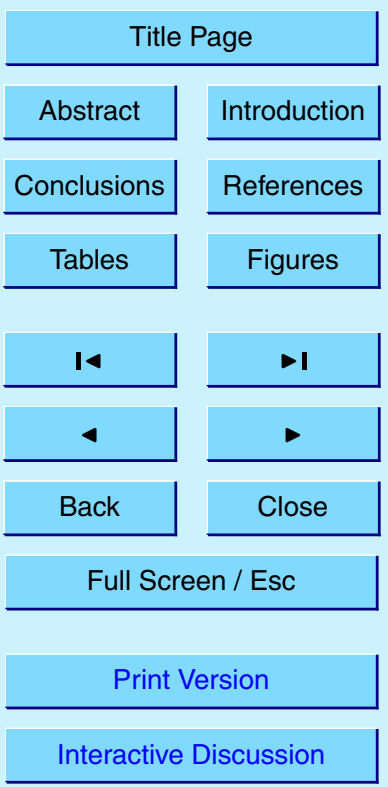

Fig. 10. Time evolution of sulfate $\left(\mathrm{SO}_{4}^{-2}\right)$ aerosol concentration $(\mathrm{mg} / \mathrm{l})$ in cloud, in $x-z$ plane at $y=8 \mathrm{~km}$, on 3 April 2000 . The dashed lines delineate the cloud boundary with cloud water mixing ratio (greater than $0.01 \mathrm{~g} / \mathrm{kg}$ ), while the solid curves represent isopleths of in cloud.

Interactive Discussion

(C) EGS 2002 


\section{ACPD}

2, 385-430, 2002

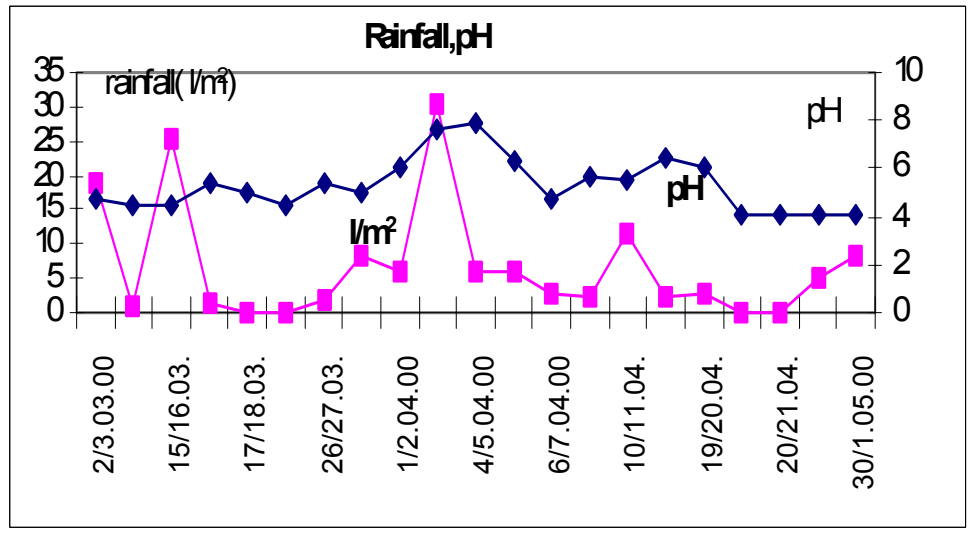

Fig. 11. The precipitation in $\left(1 / \mathrm{m}^{2}\right)$ and $\mathrm{pH}$ value in precipitation mesured on meteorological station Lazaropole, during March-April 2000.

\section{Impact of a deep convection on sulfate transport}

V. Spiridonov and M. Ćurić

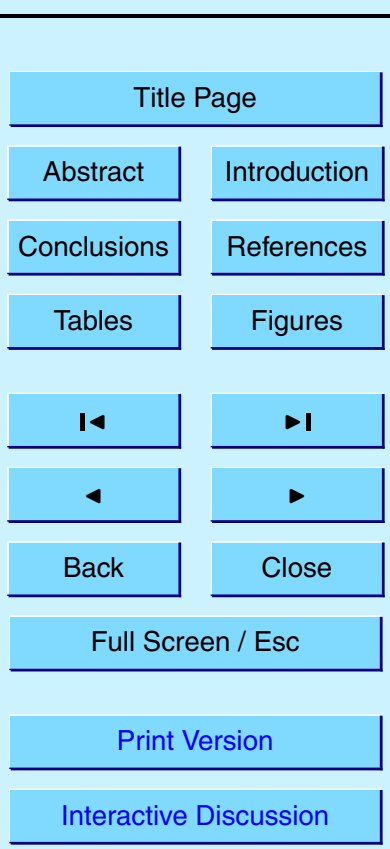

(C) EGS 2002 


\section{ACPD}

2, 385-430, 2002

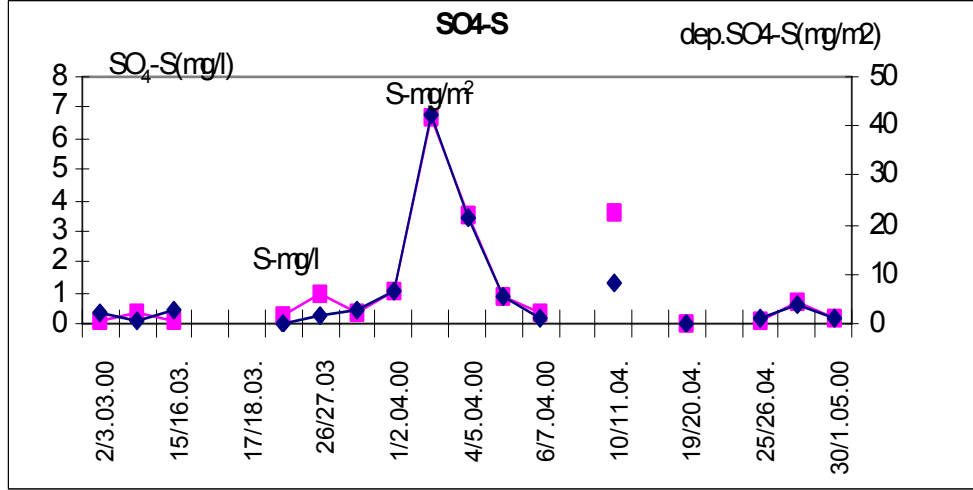

\section{Impact of a deep convection on sulfate transport}

V. Spiridonov and M. Ćurić

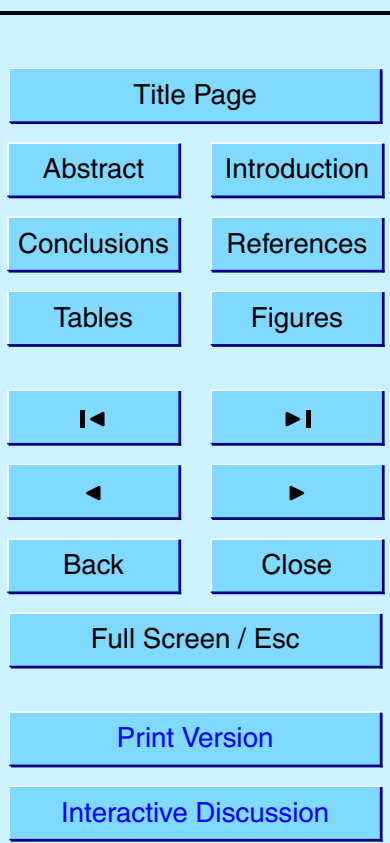

Fig. 12. The measured sulfates $\left(\mathrm{SO}_{4}^{2-}-\mathrm{S}\right)$ concentration in $(\mathrm{mg} / \mathrm{l})$ and $\left(\mathrm{SO}_{4}^{2-}-\mathrm{S}\right)$ wet deposition in $\left(\mathrm{mg} / \mathrm{m}^{2}\right)$ found in precipitation on meteorological station Lazaropole, during March-April, 2000. 

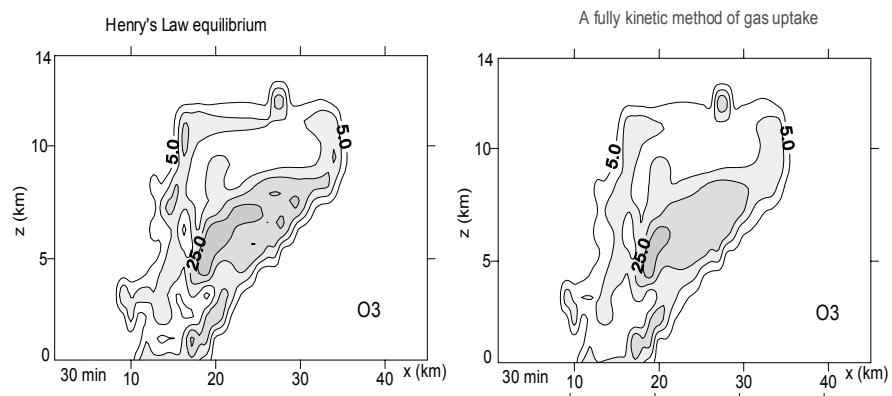

\section{ACPD}
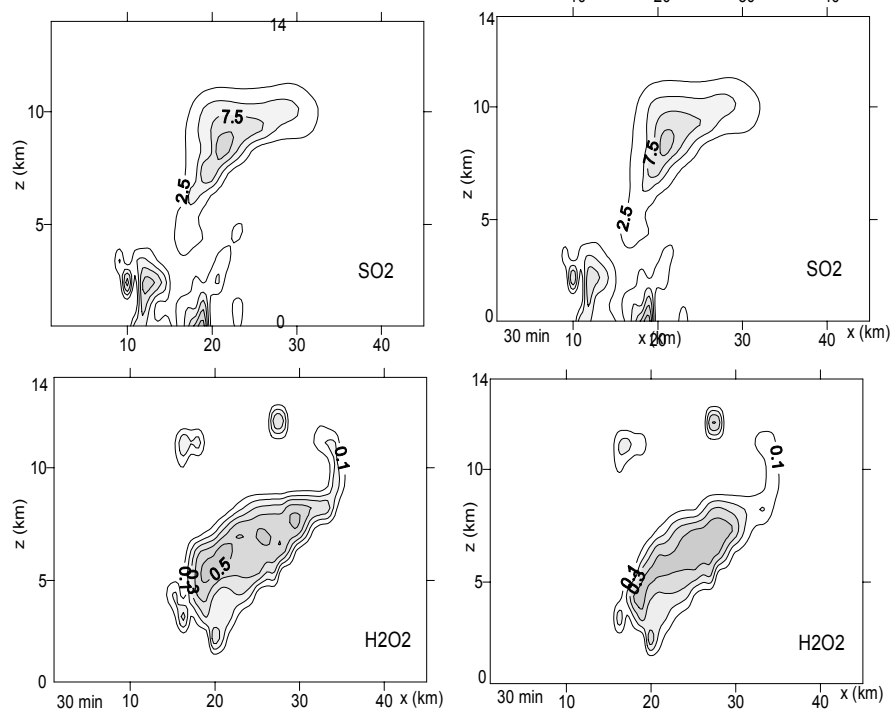

Fig. 13. Time evolution of $\left(\mathrm{O}_{3}\right),\left(\mathrm{SO}_{2}\right)$ and $\left(\mathrm{H}_{2} \mathrm{O}_{2}\right)$ concentrations in $\left(\mu \mathrm{g} / \mathrm{m}^{3}\right)$ in $x-z$ plane at $y=8 \mathrm{~km}$ in $30 \mathrm{~min}$ of the simulated cloud on 6 July 1995. Panels on the I.h.s. show results using Henry's Law assumption. The panels on the r.h.s. show distributions by including method of a kinetic gas limitations.

2, 385-430, 2002

\section{Impact of a deep} convection on sulfate transport

V. Spiridonov and M. Ćurić

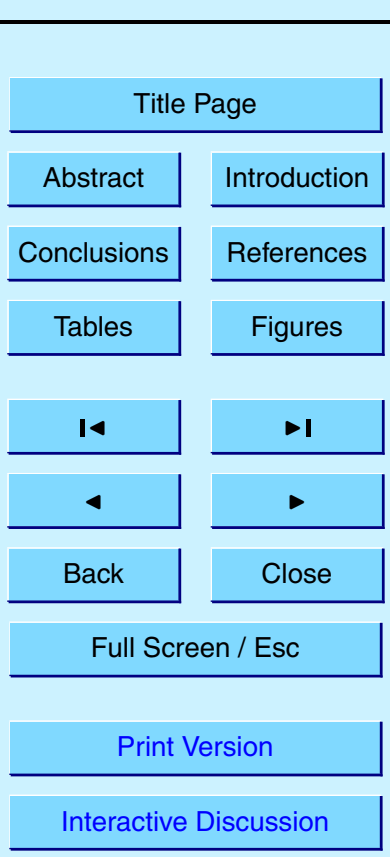

